\title{
DUSTING OFF THE ARCHIVES: WHAT ARCHIVES CAN TELL US ABOUT CHANGES IN WATER STORAGE AND STREAMFLOW DUE TO URBAN DEVELOPMENT
}

\author{
by \\ Sarah Beth Cook \\ B.A. Environmental Geoscience, West Virginia University, 2016
}

\author{
Submitted to the Graduate Faculty of the \\ Dietrich School of Arts and Sciences in partial fulfillment \\ of the requirements for the degree of \\ Master of Science
}

University of Pittsburgh 


\section{UNIVERSITY OF PITTSBURGH}

\section{DIETRICH SCHOOL OF ARTS AND SCIENCES}

This thesis was presented

by

\section{Sarah Beth Cook}

It was defended on

June 7, 2019

and approved by

Daniel J. Bain, Ph.D., Associate Professor, Dietrich School of Arts and Sciences

Emily Elliott, Ph.D., Associate Professor, Dietrich School of Arts and Sciences

Brian Thomas, Ph.D., Assistant Professor, Dietrich School of Arts and Sciences 
Copyright (C) by Sarah Beth Cook

2019 


\title{
DUSTING OFF THE ARCHIVES: WHAT ARCHIVES CAN TELL US ABOUT CHANGES IN WATER STORAGE AND STREAMFLOW DUE TO URBAN \\ DEVELOPMENT
}

\author{
Sarah Beth Cook, M.S. \\ University of Pittsburgh, 2019
}

Land-surface alteration that accompanies urbanization influences hydrologic changes within watersheds. The urbanization of a watershed can profoundly impact groundwater and surface water interaction presented as decrease in watershed storage, variability in discharge, fluctuations in low flow magnitude, increased low flow duration, and more. Although urbanization's effects on watershed hydrology have been explored in recent decades through landuse modeling, hydrological modeling, remote sensing, and empirical approaches, clarification of urbanization's effects remains a challenge due to limited availability and accessibility of high temporal resolution data. Historical streamflow records for Abers Creek in Allegheny County, Pennsylvania, provide a unique opportunity to study the effects of urbanization on watershed functions, such as storage and discharge. The discharge record (1948-1993) spans the complete residential development of the watershed as reconstructed from property records, this providing the timing and intensity of watershed development. Recession analysis was used to evaluate altered hydrologic response, particularly relationships between watershed storage and streamflow that may occur during urbanization. Sub-daily USGS stage data from archival records were converted to hourly or bihourly streamflow in Abers Creek to permit various hydrograph recession analyses on this unique streamflow record. Results relate build out to changes in hydrograph patterns identified through recession methods. Analysis of daily and sub-daily streamflow records suggest 
groundwater-surface water interactions driven by urbanization, previously only observed through modeled data or smaller datasets. Refined connections between development history and changes in hydrology allow improved mitigation of stream impacts in urban areas. 


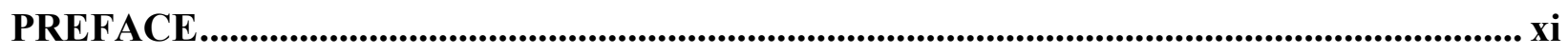

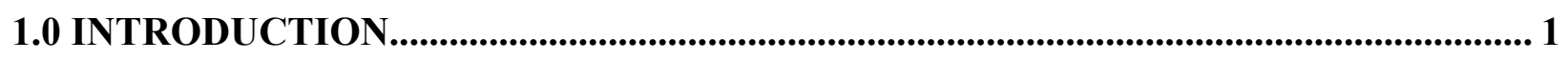

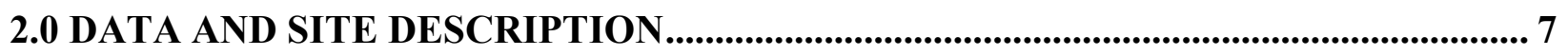

2.1 ABERS CREEK WATERSHED..................................................................... 7

2.2 WATERSHED DEVELOPMENT ........................................................................... 8

2.3 DATA DESCRIPTION .......................................................................................................... 10

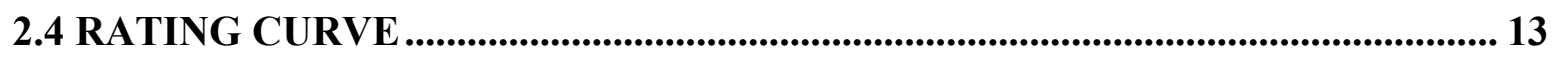

3.0 METHODS ....................................................................................................................................... 15

3.1 METHODS INTRODUCTION...................................................................................... 15

3.2 CONSTANT TIME STEP .................................................................................................. 16

3.3 VARIABLE TIME STEP ................................................................................................ 17

3.4 EXPONENTIAL TIME STEP ......................................................................................... 20

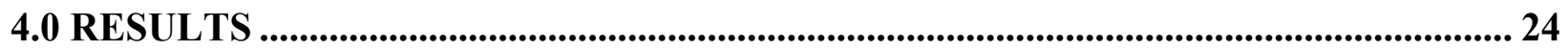

4.1 DAILY DATA ANALYSIS.................................................................................................. 24

4.2 SUB-DAILY DATA ANALYSIS.................................................................................. 27

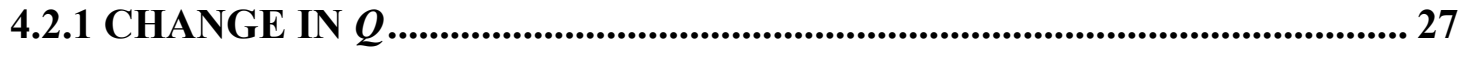

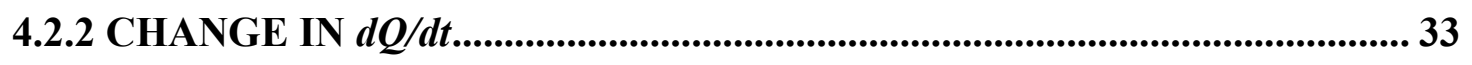




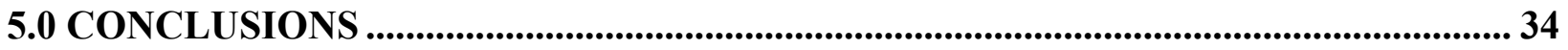

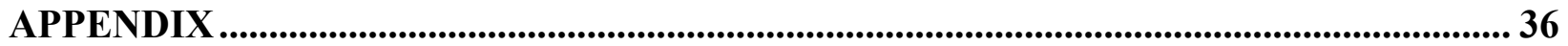

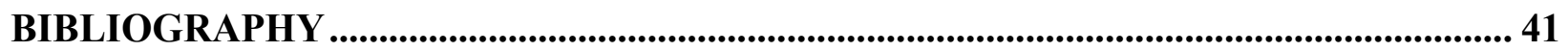




\section{LIST OF FIGURES}

Figure 1 - Illustration of conceptual hydrograph recession behavior. Movement of the recession cloud along the $\mathbf{x}$-axis " $(\log ) \mathrm{Q}$ " suggests increased or decreased watershed storage. Movement along the y-axis $\left("(\log )-\mathrm{dQ} / \mathrm{dt}^{\prime \prime}\right)$ indicates change in the time

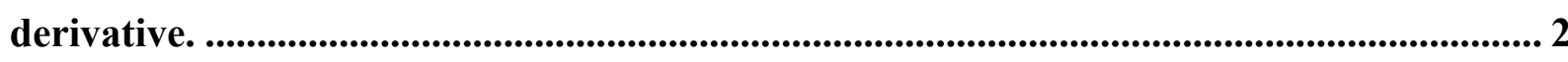

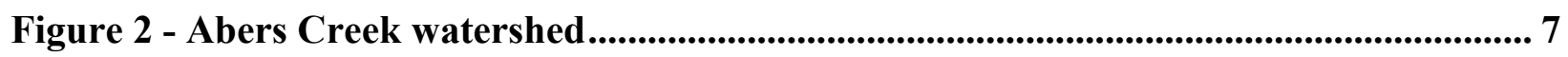

Figure 3 - Development of Abers Creek watershed. Snapshots show the build out in the catchment. Properties are colored solid black once the structure in the property is completed. Only data from Allegheny County is depicted.............................................9

Figure 4 - Abers Creek population density per km2 (Left), Abers Creek building density per

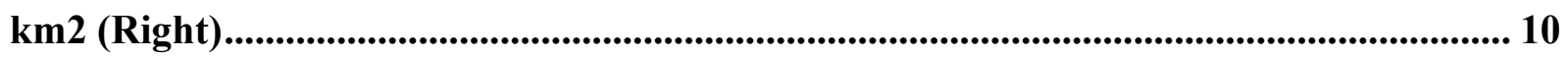

Figure 5 - Example of sub-daily stage height data for Abers Creek........................................ 11

Figure 6 - Example of early drum data for Abers Creek. The line drawn indicates the rise

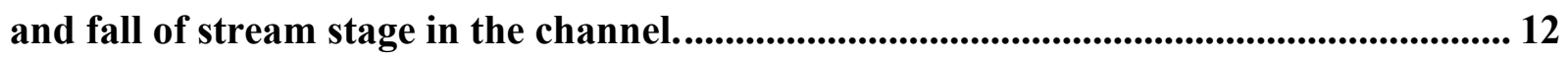

Figure 7 - Rating curve for Abers Creek ........................................................................... 13

Figure 8 - CTS illustration where time increment remains constant.................................... 16

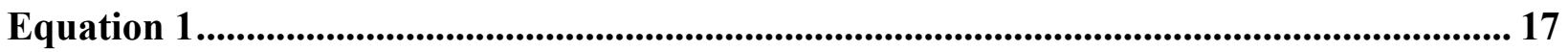

Figure 9 - Numerical artifacts in a recession plot. The linear points circled near the lower portion of the plot are caused by data processing................................................................ 17

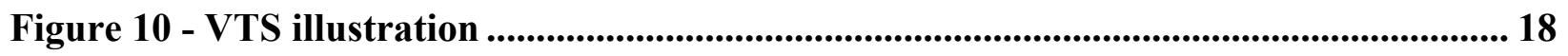

Figure 11 - ETS illustration where the time increment increases exponentially along a recession. 20 
Figure 12 - Daily discharge data processed using constant time step approach. 1970 data was used as a baseline and appears in light grey. While the blue data points correspond to the year as labeled. Artifacts can be observed in the lower portion of the plots. 26

Figure 13 - Daily data using variable time step approach exhibits similar regimes throughout. 1970 data was used as a baseline and appears in light grey (a) 1975, (b) 1980, (c) 1985, (d) 1990. 27

Figure 14 - CTS Sub-daily data: (a) 1975, (b) 1980, (c) 1985, (d) 1990. Grey points correspond to 1970 data. 29

Figure 15 - VTS sub-daily recession plots: (a) 1970, (b) 1975, (c) 1980, (d) 1985, (e) 1990 .. 30

Figure 16 - ETS sub-daily recession plots: (a) 1970, (b) 1975, (c) 1980, (d) 1985, (e) 1990 .. 31

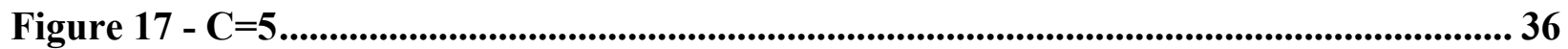

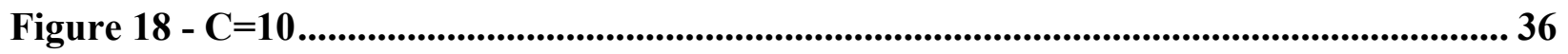

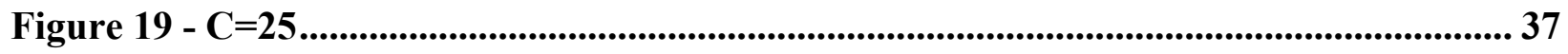

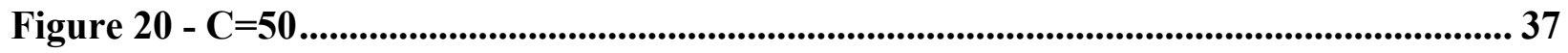

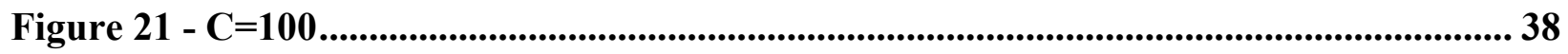

Figure 22 - Comparison of daily (blue) and sub-daily (orange) discharge data for 1970 .... 38

Figure 23 - Comparison of daily (blue) and sub-daily (orange) discharge data for 1975 .... 39

Figure 24 - Comparison of daily (blue) and sub-daily (orange) discharge data for 1980 ... 39

Figure 25 - Comparison of daily (blue) and sub-daily (orange) discharge data for 1985 .... 40

Figure 26 - Comparison of daily (blue) and sub-daily (orange) discharge data for 1990 .... 40 


\section{LIST OF EQUATIONS}

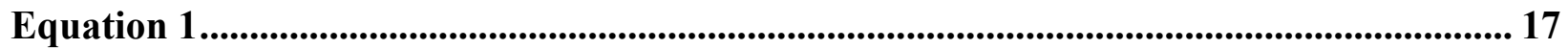

Equation 2 2........................................................................................................................................ 19

Equation 3............................................................................................................................................... 19

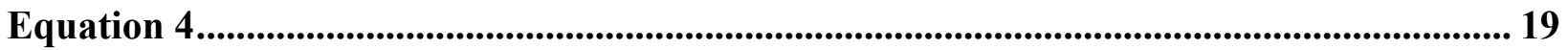

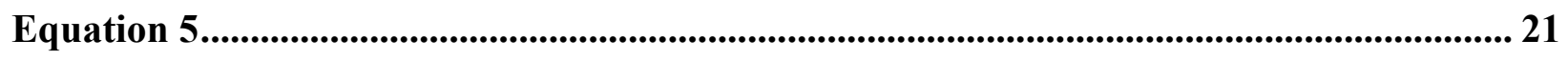

Equation 6.................................................................................................................................... 21

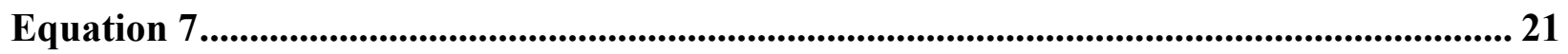

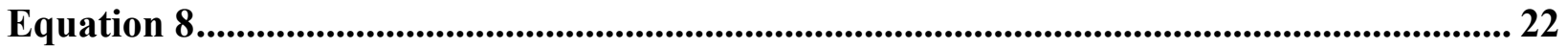

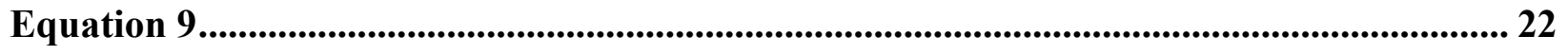

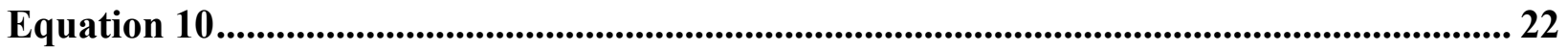

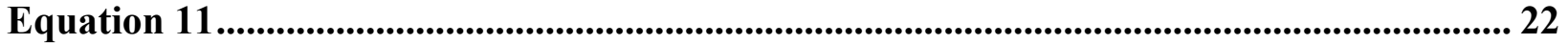




\section{PREFACE}

I would like to express my gratitude to my advisor, Dr. Brian Thomas, for the continuous support throughout my graduate career. I appreciate your patience, knowledge, guidance, and mentorship more than you know. I would also like to sincerely thank Dr. Daniel J. Bain and Dr. Emily Elliott for serving on my committee and for always being so kind and supportive. Furthermore, I would like to thank the faculty, staff, and graduate students in the department for all of the great advice, encouragement, and friendships. I would also like to acknowledge Jamie McCoy at the US Geological Survey for being incredibly accommodating and helpful throughout the data collection process. I would like to extend my thanks to Dr. Clément Roques for providing useful Matlab code to assist in my analysis. Finally, I must express my sincere gratitude and love to my parents, family, and friends for providing me with unfailing support and continuous encouragement in everything I do. This accomplishment would not have been possible without them. Thank you! 


\subsection{INTRODUCTION}

In hydrology, the dynamic relation between watershed storage and discharge is essential to understand the intertwined connection between groundwater and surface water. The factors which control this association are at the center of catchment science (Sophocleous, 2002; Kalbus et al., 2006; Fleckenstein et al., 2010). Investigating streamflow hydrograph recession analysis allows for a conjectural evaluation of the streamflow and surface water changes, assuming that the dynamic is defined in large part by aquifer characteristics and groundwater interaction (Ghosh, 2015; Thomas et al. 2015). In most studies, including this one, hydrological recessions are conceptualized as continually decreasing flows that result from drainage of catchment storages (i.e. baseflow (Hall, 1968)) during periods of little or no precipitation.

Many previous studies have evaluated hydrograph recessions to further our understanding of watershed function and processes controlled by watershed storage. Werner and Sundquist (1951) introduced a concept whereby the recession curve can be approximated by the sum of three exponential functions with different coefficients. A defined set of conceivable equations of recession curves including the simple exponential, double exponential, and hyperbolic (Toebes and Strang, 1964; Toebes et al., 1969) conveyed conditions under which a certain type of curve could be anticipated. A breakthrough in recession research was presented by Brutsaert and Nieber (1977) that related discharge, $Q$, and storage, $S$, in attempt to analyze river discharge behavior at the watershed scale by estimating hydrograph recession parameters from a log-log plot of the time derivative of streamflow $(d Q / d t)$ versus $Q$, known as a recession plot. Wide application of the recession approach advanced by Brutsaert and Nieber (1977), termed the constant time step (CTS) method, estimates $d Q / d t$ using a backwards difference estimator (Thomas et al., 2015). This 
technique for analyzing streamflow recession behavior has been extensively used to characterize hydrological properties within watersheds through analyses of multiple recession events (Brutsaert and Nieber 1977, Troch et al. 2013). Analyses of single recession events have grown in popularity due to extreme variability in responses within a watershed (Rupp and Selker 2006b, Dralle et al., 2017, Thomas et al., 2015).

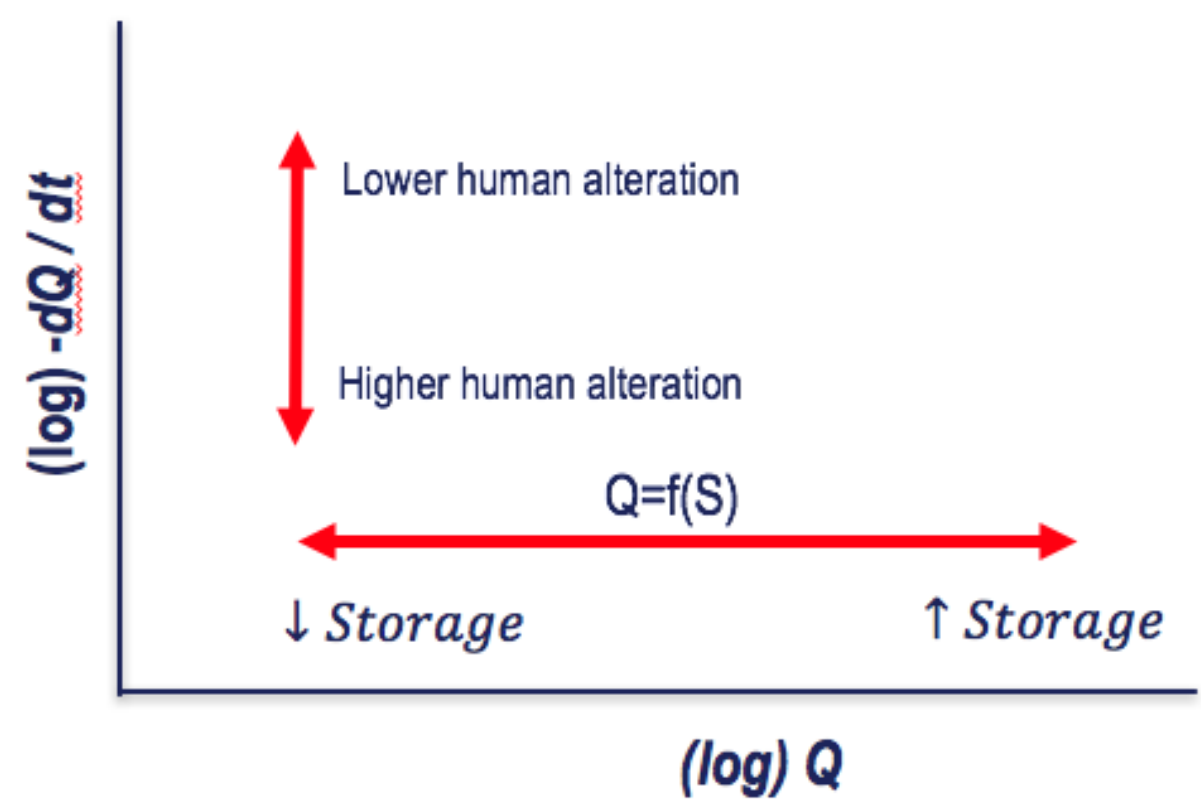

Figure 1 - Illustration of conceptual hydrograph recession behavior. Movement of the recession cloud along the $x$-axis " $(\log ) Q "$ suggests increased or decreased watershed storage. Movement along the y-axis ("(log) $\left.\mathrm{dQ} / \mathrm{dt}^{\prime \prime}\right)$ indicates change in the time derivative.

While the CTS method is commonly applied in traditional recession analyses, it has been shown to introduce error and biases within the recession data cloud, especially in late-time recessions, where artifacts tend to be introduced (Rupp and Selker, 2006). An artifact refers to any anomaly within the perception or representation of data and can be introduced via processing 
techniques. Rupp and Selker (2006) suggest that the use of a constant time step is an insufficient representation of data, a result further supported by Thomas et al. (2015), given that the linear artifacts may influence parameter estimations. With hopes of alleviating this issue, Rupp and Selker (2006) introduced a novel method proposing $\Delta t$ for each observation in time may be scaled to the observed change in discharge $\Delta Q$, termed here as the variable time step method (VTS).

The VTS method illustrates the relationship between $d Q / d t$ and $Q$ where standard methodology, such as the CTS approach, fails in data where $d Q / d t$ fluctuates by orders of magnitude during recession; hence the scaling of $\Delta t$. Small-scale hydrograph fluctuations can result in excluding large portions of the hydrograph from analysis, as it's interpreted that the recession has ended when in fact is has not. What may be an appropriate $\Delta t$ during a particular time increment may be too large or too small for an earlier or later time; thus, producing numerical artifacts derived from the estimate of $d Q / d t$. Rupp and Selker (2006) found data exclusion and numerical artifacts to be most prominent within latter hydrograph recession where Q may be reported as unchanging or increasing over time due to limitations of stage-discharge relations and coincidentally excluding corresponding $d Q / d t$ calculations from being reported (Kirchner, 2009). More recently, Roques et al. (2017) have further advanced extraction of $d Q / d t$ from recession hydrographs by the use of exponential curves to represent the recession, from which $d Q / d t$ can be estimated as the recession proceeds. Roques et al. (2017) systematically showed that the method, referred to here as the exponential time step method (ETS), eliminated artifacts within the recession plot and was able to more accurately retrieve recession parameters than previously applied methods.

Empirical methods have been used to link observed changes in recession plot clouds to human interferences. Wang and Cai (2010) introduced methods to account for human water uses 
in recession cloud plots by including groundwater pumping and return flows into equations proposed by Brutsaert and Nieber (1977). Wang and Cai (2010) deliberated how hydrologic factors affected the determination of the recession slope curve and the cloud shape of the data points in a recession plot. The authors assumed data cloud shapes within the recession plot may be affected by factors such as physical characteristics of the drainage system, data uncertainties, spatial heterogeneity of groundwater drainage, drainage from bodies of water, and human interferences. Wang and Cai (2009) introduced an empirical method allowing estimates of human water uses, like groundwater pumping and return flow, to be included within recession plots.

Other studies have investigated the behavior of baseflow as a function of watershed characteristics, climate, and geomorphology. Brandes et al. (2005) examined connections between hydrologic variables (baseflow recession rates and $\mathrm{Q}_{7,10}$ ), finding that drainage density, landscape slope, bedrock geology, and soil infiltration rate exert the most influence on recessions, thus suggesting that baseflow is largely controlled by invariable watershed characteristics. Biswal and Marani (2010) linked river network morphology with recession curvature (e.g. the shape of a recession on a recession plot). The authors argue that the power-law form of $d Q / d t$ vs. $Q$ stems from the underlying morphological structure of the channel network, thus directly linking recession shape to geomorphological recession flow models (Biswal and Kumar, 2012). Shaw et al. (2012) hypothesized that the change in the recession plot intercept derived from fitting lines to recession cloud data results from spatial heterogeneities in seasonal variations and antecedent conditions within the watershed. Thomas et al. (2013) quantified the sensitivity of geology, geomorphology, anthropogenic factors, and topography in the influence of variations of the baseflow recession constant, finding that hydrograph recessions are equally sensitive to anthropogenic variables as geomorphic variables. 
Urban development and associated water management schemes including low impact development and wastewater treatment/discharge have been shown to influence low flow dynamics (Sophocleous, 2002; Liu et al., 2013; Brandes et al., 2005; Meyer, 2005; Hogan et al., 2014). Rural and urban watershed comparative studies (Barringer et al., 1994; Schwartz and Smith, 2014; Hopkins et al., 2015) sought to link changes in baseflow contributions due to urban development. Bhaskar et al. (2016) identified changes in hydrograph recessions attributed to low impact development in urban watershed. Contrasting to urban stormflow, largely regarded to cause flashiness in hydrographs due to increased impervious cover, Hopkins et al. (2015) suggest that urban baseflow exhibits important diversity in responses, controlled by factors including impervious cover, infrastructure leakage, evapotranspiration, and stormwater management (Bhaskar et al., 2016). This suggests that the urbanization trajectory has a strong influence on the magnitude and timing of hydrologic changes within watersheds.

Recession analysis was used to evaluate altered hydrologic response, particularly relationships between watershed storage and streamflow that may occur during urbanization, whereby shifts in the recession cloud (Figure 1) are attributed to recorded urban development in Abers Creek. Shifts in the recession cloud can indicate either an increase or decrease in discharge along the $\mathrm{X}$-axis, as well as an increase or decrease in the time derivative of discharge along the Y-axis. In this study, I evaluate change in watershed storage as a function of discharge $(Q=f(S))$ with the use of post-urbanization stage data by applying various recession methodologies to a small, urbanized watershed that underwent documented development concurrent with discharge records. For this study, an increased discharge $(Q)$ is assumed to indicate increased watershed storage (S). A shift in the recession cloud towards an increased $d Q / d t$ implies an increased amount of human alteration within the watershed. The overarching hypothesis of this study is that build- 
out of Abers Creek has led to hydrologic alterations observable through hydrograph recessions. I hypothesize that different recession methodologies (e.g. CTS, VTS and ETS) extract different information from hydrograph recessions, thus providing insight into urban recessions and changes in recessions as a result of urban development. 


\subsection{DATA AND SITE DESCRIPTION}

\subsection{ABERS CREEK WATERSHED}

Abers Creek watershed is a relatively small sub-watershed $\left(11.4 \mathrm{~km}^{2}\right)$ of the larger Turtle Creek - Brush Creek watershed located just northeast of Pittsburgh in Plum Borough of Allegheny County, Pennsylvania (Figure 2). Abers Creek lies within the estern Allegheny Plateau and is characterized by hilly terrain dissected by perennial streams within valleys that tend to be underlain by horizontally bedded sedimentary rock (Wagner, 1970).

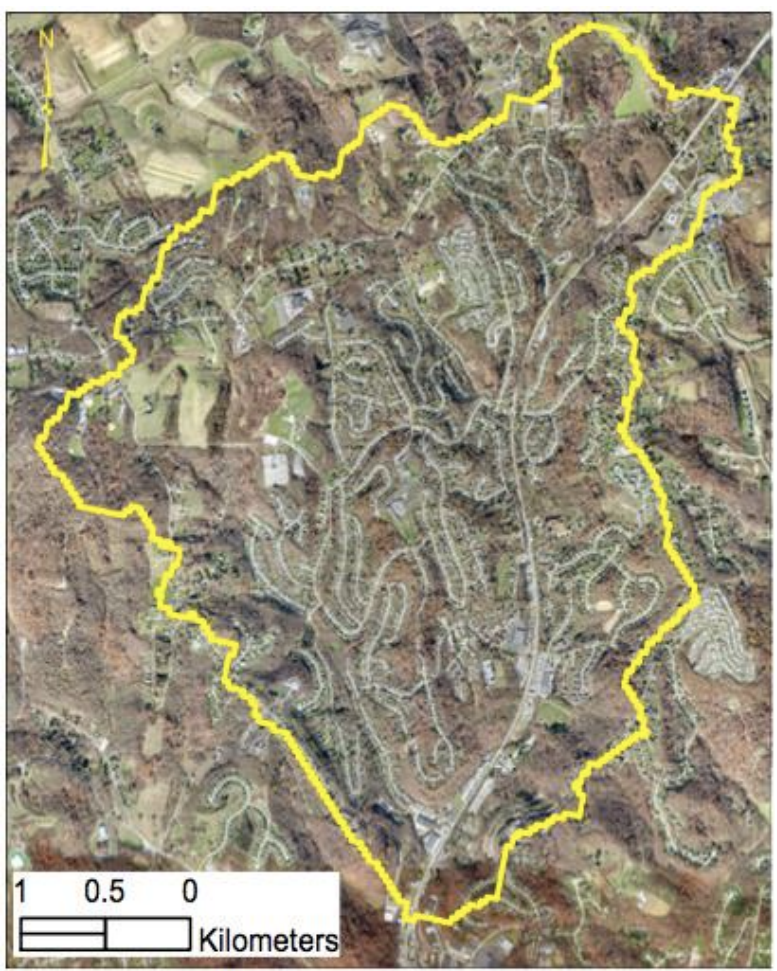

Figure 2 - Abers Creek watershed. 
Streamflow records for Abers Creek provide a unique opportunity to study the influence of urbanization on watershed processes, particularly changes in watershed storage and baseflow contributions which are known to vary in urbanized watersheds (Hopkins et al., 2015). The discharge record (1948-1993) spans the complete residential development of the watershed (Section 2.2). Daily streamflow records from 1948 - 1993 are currently available via the USGS Waterdata portal. In this analysis, I wish to apply hydrograph recession methods that require temporal data at resolutions below a daily time step (Section 3). Sub-daily stage data, however, is only accessible at the U.S. Geological Survey as archived files of tabular and drum records, thus requiring data extraction methods as discussed in Section 2.3.

\subsection{WATERSHED DEVELOPMENT}

Build-out of the watershed was reconstructed in a study by Hopkins et al. (2015) using building density records, property tax records, and basin area to provide the timing and intensity of watershed development (Figure 3). Property tax-assessment records were only available for about $82 \%$ of Abers Creek and basin area in Allegheny County was used to approximation building densities. Hopkins et al. (2015) assumed each parcel contained one building. As stated in Hopkins et al. (2015), these assumptions could be underestimated in earlier years due to substitution of historical houses during redevelopment, therefore, leading to the possibility of error in Figure 4. The study deemed the estimates acceptable for evaluating general growth trends and also verified the consistency of building density records by cross-checking building density data with U.S. Census records. 

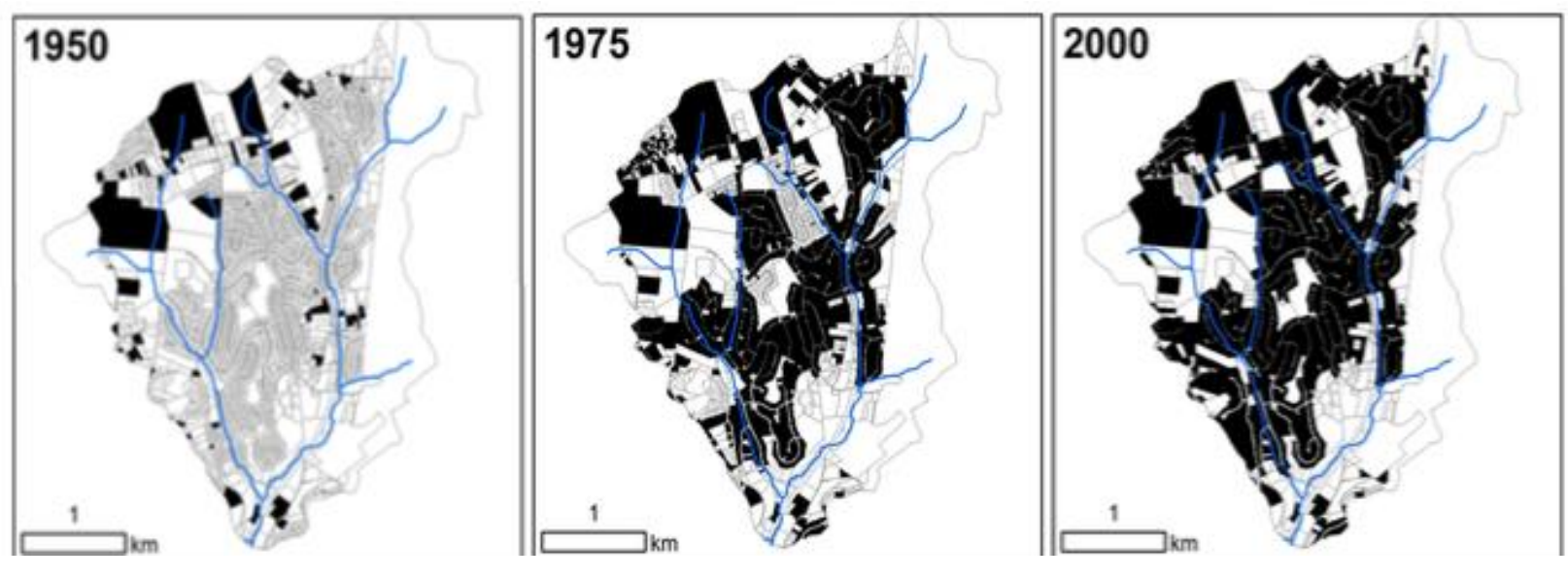

Figure 3 - Development of Abers Creek watershed. Snapshots show the build out in the catchment. Properties are colored solid black once the structure in the property is completed. Only data from Allegheny County is depicted.

Abers Creek watershed experienced a large increase in population density and building density between 1955 and 1970 (Figure 4, Hopkins et al. 2015). Development growth rates plateaued after 1970 and were followed by a decline in population density starting in 1980. In Abers Creek, the majority of building density (70\%) occurred during the peak growth period, with slow but limited growth following the peak growth period (Hopkins et al. 2015). The sudden change in development patterns and changes in flow, both observed in Hopkins et al. (2015) study, suggest that human and hydrologic systems can be strongly linked, especially when development is extremely rapid and concentrated, as observed in Abers Creek. Hopkins et al. results validated that rapid urbanization can lead to significant shifts in the flow regime like increased flashiness, reduced baseflow, infiltration and evapotranspiration. 

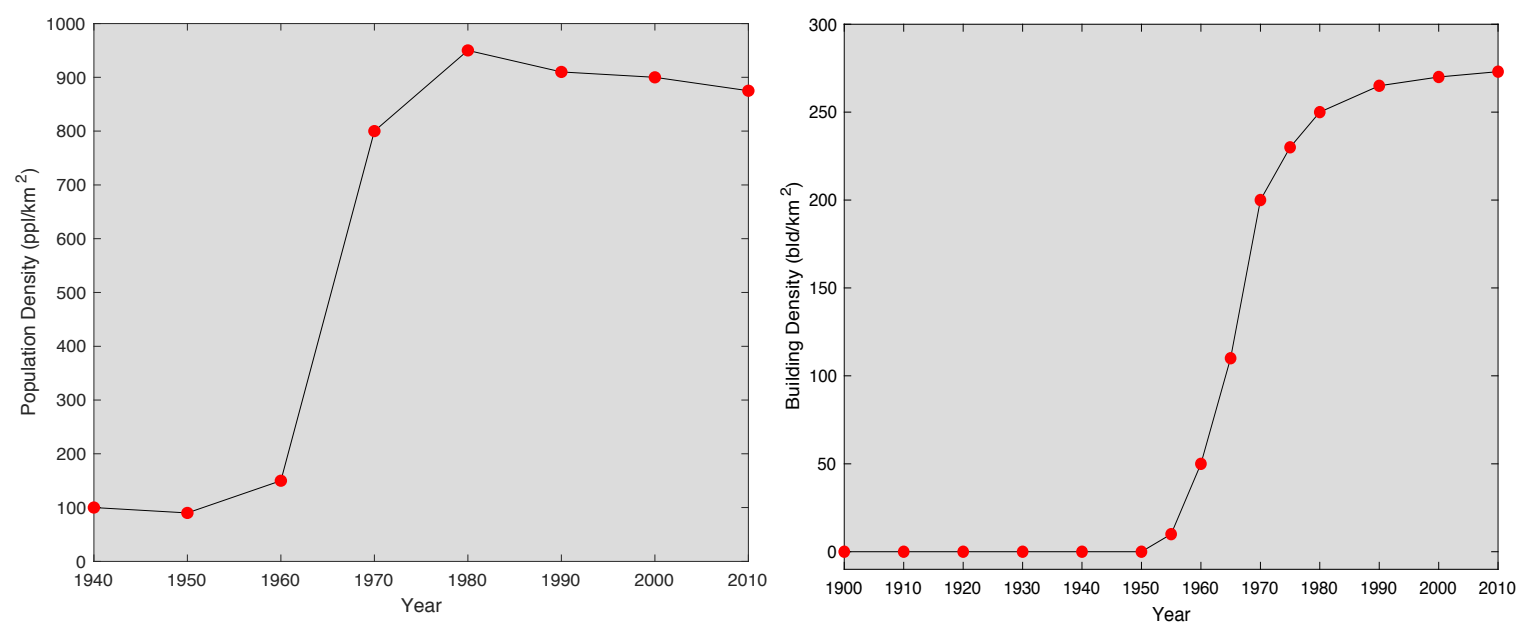

Figure 4 - Abers Creek population density per km² (Left), Abers Creek building density per km² (Right).

\subsection{DATA DESCRIPTION}

Technology for measuring and recording data for streamflow has significantly improved over the years (USGS n.d.). In the early 1900's, stage recorders used a float that moved up and down with the water surface height. The float's movements traced the stage record onto graph paper taped to a revolving drum and then manually interpreted. Electronic data compilation began in the early 1960s, when recorders were developed that punched stage readings into paper. tapes (USGS n.d.). 


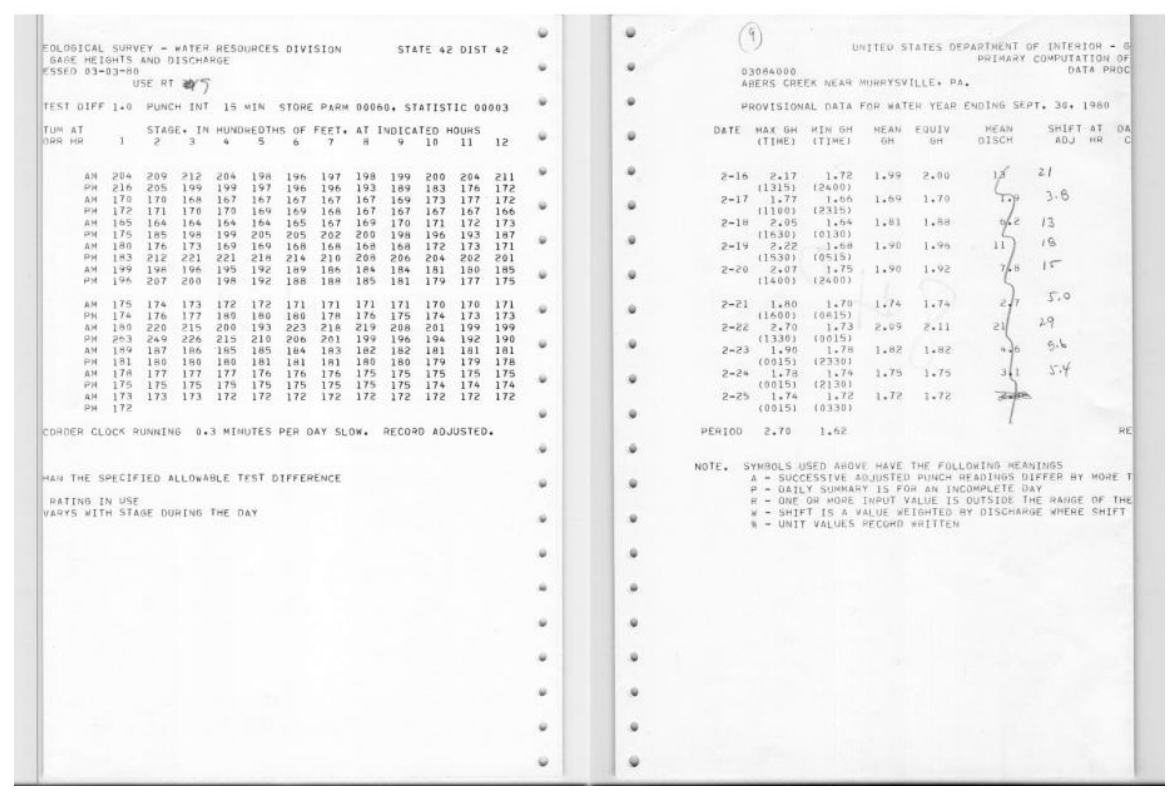

Figure 5 - Example of sub-daily stage height data for Abers Creek.

These tapes were able to be read by a computer such that data could be stored in electronic files. During the 1970s, data recorders with satellite-telemetry equipment were initiated which allows data transmission to a satellite and transfers to the USGS (USGS n.d.).

The evolution in USGS stream gaging was captured at Abers Creek, thus opening the possibility of using streamflow stage records to identify additional information in sub-daily hydrographs in urbanizing watersheds. Sub-daily data for Abers Creek watershed was acquired from historical documents stored at the USGS office in Pittsburgh, PA. Hard copies from 19481993 encompass stage height in continuous, bihourly, and hourly increments depending upon the year it was collected (Figure 5). While some large outliers occurred within sub-daily data, these values do not affect recession analyses and is likely attributed to error in data extraction or tabular records from the USGS. Due to large variability in the record condition and record type, data compilation and extraction was time intensive; as much of the older data consists of graphical, continuous, drum records rather than tabular (Figure 6). 5-year incremental of tabular, sub-daily 
data from 1970 to 1990 was used for this study. The sub-daily data consisted of, on average, 30 to 40 scans per record year (Figure 5). Once each year was scanned, the process of extracting information from the scans could commence. Scanned stage height data for 5-year increments of tabular data from 1970 was extracted using open source, online OCR (optical character recognition) technology, which allows scanned documents to be useable in data analysis.

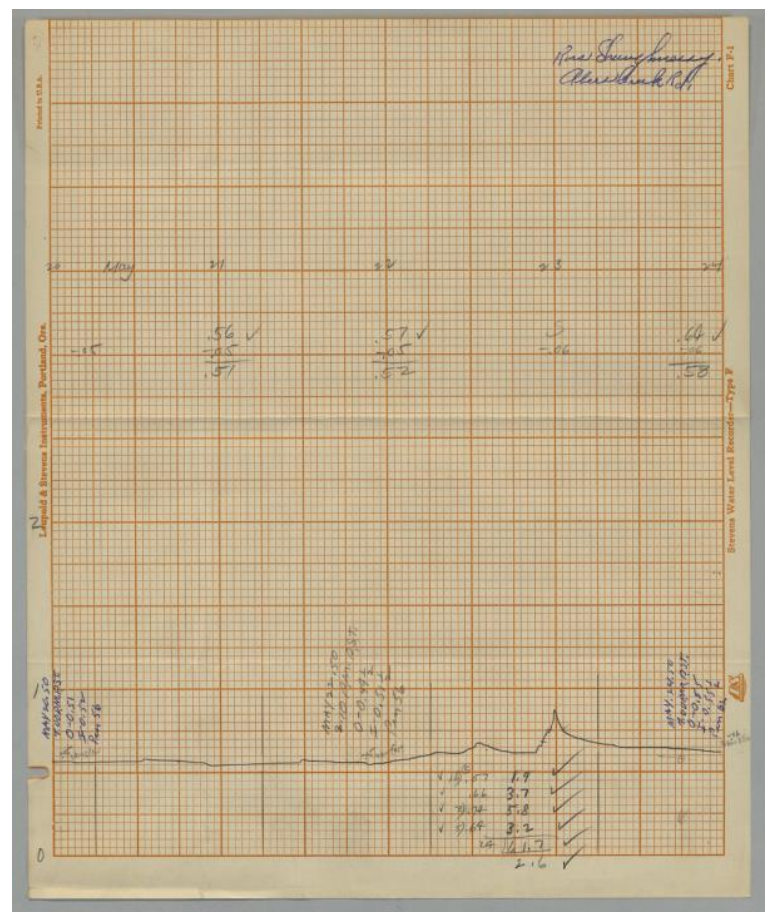

Figure 6 - Example of early drum data for Abers Creek. The line drawn indicates the rise and fall of stream stage in the channel.

In order to determine the applicability of sub-daily data to that of daily data, daily averages for sub-daily discharge were taken and plotted against daily discharge data (See Appendix). Large spikes in discharge occur in sub-daily data, while low flow measurements are rather similar. These spikes are likely attributed to error in data extraction and since recession analyses are only concerned with low flow data, these spikes can be disregarded. 


\subsection{RATING CURVE}

In order for water or stage height to be converted to a discharge volume, a relationship must be established between them by constructing a rating curve (USGS n.d.). A rating curve was constructed using field data measurements from the USGS Waterdata portal for Abers Creek. The field data includes all necessary information to construct a rating curve, including measured streamflow, gage height, measurement rating (how accurate a measurement is), and control (e.g. the amount of debris present).

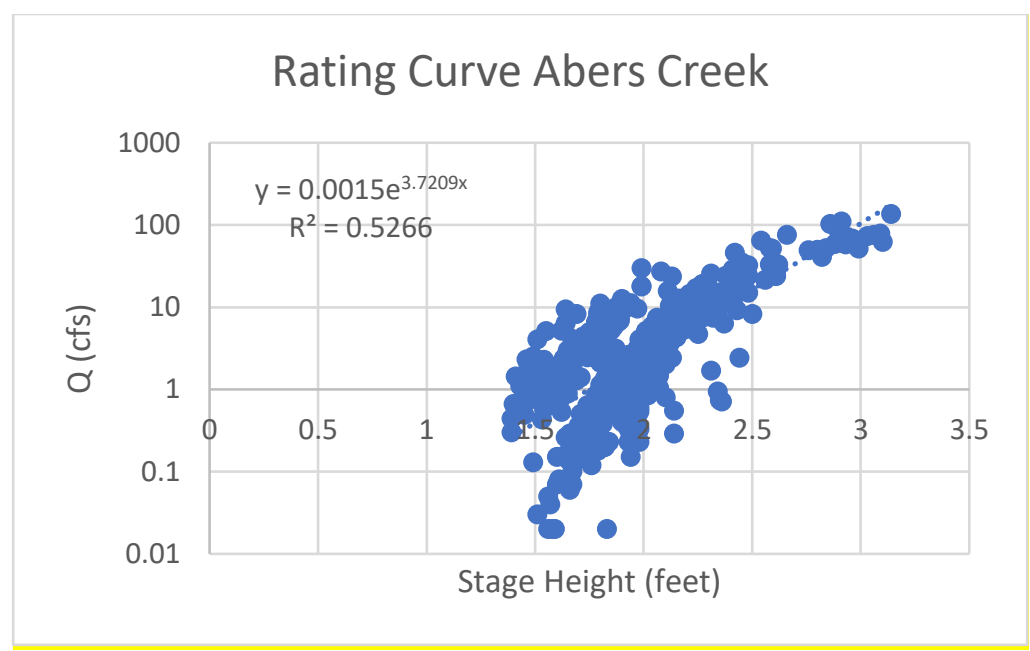

Figure 7 - Rating curve for Abers Creek.

The rating curve depends on the hydraulic characteristics of the stream channel and floodplain and can be influenced by subtle changes to a stream channel, like vegetation growth, shifting of sediment or erosion, extreme changes due to flooding, or man-made changes (USGS n.d.). These variables can be explored and manipulated from the field data measurements to find a best fit curve for a particular data set. The final rating curve (Figure 7) relates discharge versus 
stage height and yields an equation that allows for the conversion of stage height into a volume of water discharged.

When applying recession methodologies to sub-daily data for Abers Creek, daily gage height data with corresponding dates and times was imported into Excel for five year increments. Gage height was converted to discharge, $Q$, for sub-daily data using the equation produced from the constructed rating curve. 


\subsection{METHODS}

\subsection{METHODS INTRODUCTION}

Recession analysis was used to evaluate altered hydrologic responses in Abers Creek, particularly relationships between watershed storage and streamflow that may occur during urbanization. Application of various methodologies to estimate the time derivative of streamflow (CTS, VTS, ETS) were applied to daily and sub-daily records for 1970, 1975, 1980, 1985 and 1990 for months between April and September. Yearly records generally stemmed from October to September of the following year, however, some years missed data - leading to using data from April to September. For this study, I hypothesized that varied approaches would produce identifiable and discrete patterns within recession plots (Figure 1) which could be attributed to urbanization intensity established by Hopkins et al (2015) for Abers Creek (Figure 3).

For each of the following methods, a three-day moving average of $Q$ was calculated to negate streamflow measurement error and fluctuations as well as to isolate suitable recession hydrographs for analysis (Vogel and Kroll, 1996). Recessions were isolated by defining an increase in $Q$ as the end of the recession. Therefore, the beginning of a recession is identified as when a 3-day moving average begins to decrease and ends when a 3-day moving average begins to increase. Nearly all recession studies set a minimum duration for recession events. Explanations for this choice contrast, such as the removal of noise, the need for capturing late time flow processes, and data quality concerns (Dralle et al., 2017). Recessions with lengths greater than or equal to 2 days were used for this study. The first 3 points of the recession were discarded for estimation of the baseflow recession parameters to reduce the influence of additional runoff 
processes (Thomas et al., 2015). The time derivative of streamflow, $d Q / d t$, was calculated using different recession analysis approaches as described in Sections 3.2-3.5. Data are then plotted as $d Q / d t$ vs. $Q$ in log scale to observe recession behaviors for any given period. To qualitatively compare shifts in the data cloud between years, a reference line was implemented for each recession plot.

\subsection{CONSTANT TIME STEP}

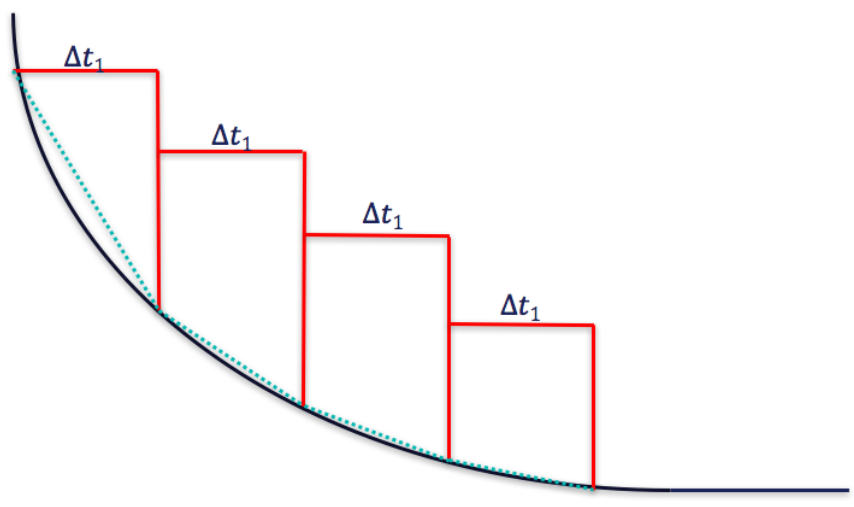

Figure 8 - CTS illustration where time increment remains constant.

The constant time step approach (Brutsaert and Nieber, 1977) is a widely adopted method in recession analysis. The original intent of the CTS approach was to remove uncertainty when implementing an appropriate time reference for a hydrograph recession (Figure 8). The relation between $Q$ and $S$ may then be amalgamated with the groundwater continuity equation yielding 
To calculate $d Q / d t$, a backwards difference estimator is used following Brutsaert and Nieber (1977).

\subsection{VARIABLE TIME STEP}

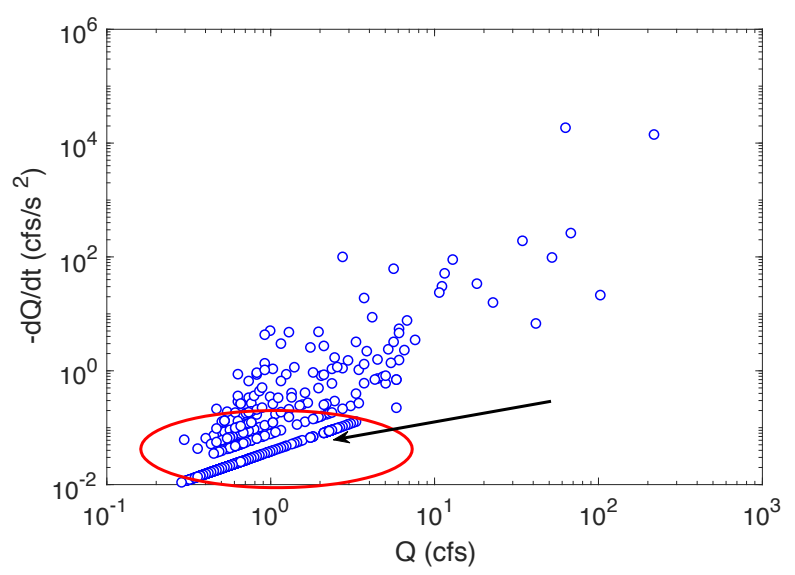

Figure 9 - Numerical artifacts in a recession plot. The linear points circled near the lower portion of the plot are caused by data processing.

Rupp and Selker (2006) introduced a variable time step (VTS) method that estimates $d Q /$ $d t$ based upon the derivation of recession segments at varying durations and appropriately scaled to the recorded drop in discharge $\Delta Q$, rather than applying constant time steps as used in Brutsaert and Nieber (1977) (Figure 10). A plus to this method is the reduction of artifacts in data, whereas streamflow recession data presented using constant $\Delta t$ can lead to misconstructions of the underlying relationships in the streamflow data where $Q=f(S)$. 
Artifacts are anomalies in the perception or representation of data and can be introduced via processing techniques (Figure 9). In recession plots, artifacts tend to present as clustered, usually horizontal, lines of points within the recession plot and can lead to issues when interpreting results. What may be an appropriate $\Delta t$ at one point in time for $d Q / d t$, may be too small or too large at other points in a recession. Therefore, constant $\Delta t$ leads to upper and lower data boundaries in plots of $-d Q / d t$ and $Q$ that are merely numerical artifacts (Rupp and Selker, 2006).

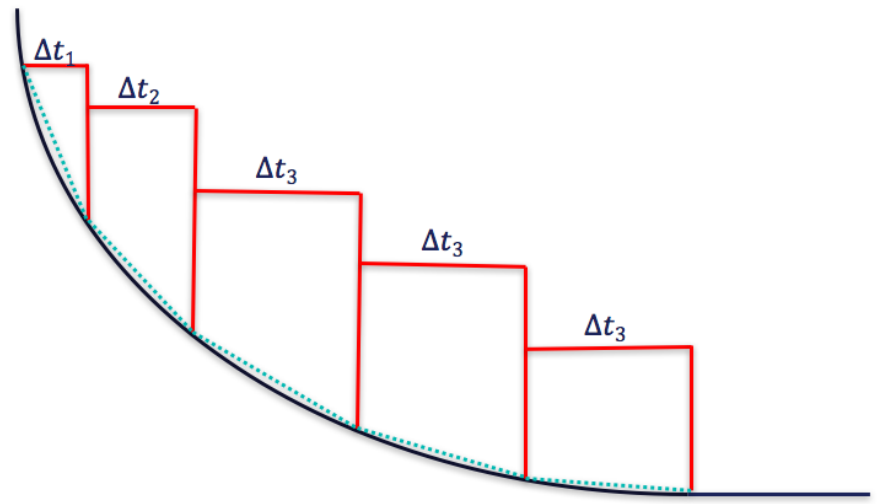

Figure 10 - VTS illustration.

Therefore, with the VTS method, where $\Delta Q$ is high, there is a lot of data regarding hydrograph changes, and hence $\Delta t$ can be low. When $\Delta Q$ is low, we need longer portions of the hydrograph to get information, thus $\Delta t$ must be higher. Artifacts can be generalized as errors in the information extracted from the hydrograph. Using the CTS methods, we get artifacts in the southwest quadrant of the recession plot since this is where information is missing. However, while artifacts are greatly reduced with the use of VTS methodology from that of CTS, they are still present in recession plots. 
Rupp and Selker (2006) suggested that, preferably, $\Delta t$ would be selected such that the data points remain within upper and lower envelopes. Envelopes are defined as the upper and lower boundaries of data once plotted. The approach introduces a time increment $\Delta t$ that is correctly scaled to the detected drop in discharge $\Delta Q$. To do this, the rate of change in time of discharge along with the corresponding discharge can be calculated by:

$$
\begin{gathered}
\frac{d Q}{d t}=\frac{Q_{i}-Q_{i-j}}{t_{i}-t_{i-j}}, \quad i=2,3,4, \ldots, n \text { and } 0<j<i \\
Q=\frac{1}{(j+1)} \sum_{k=i-j}^{i} Q_{k}
\end{gathered}
$$

Equation 3

Here, $i$ is representative of data recorded at certain time increments, while $j$ is the number of time increments over which $d Q / d t$ is calculated. The time interval $t_{i}-t_{i-j}$ corresponds to difference in $Q$ values $Q_{i-j}-Q_{i}$. Operationally, a step backwards in time from the $i$ th value of steps $j$ to reach Eq. (6) with $C$ being a constant $\geq 1$;

$$
Q_{i-j}-Q_{i} \geq C\left[Q\left(H_{i}+\varepsilon\right)-Q_{i}\right]
$$

Equation 4

Where $\varepsilon$ is a function of the measurement precision, $H$ is stage height at $i$ th observation, and $Q_{i}$ is discharge at $i$ th observation in a recession.

For this study $C=10$ as it provided the best results with this particular dataset as well as to remain consistent with recent applications of the ETS method (Roques et al., 2017). While $C=$ 25 looks visually viable as it reduces scatter, it is desirable that $C$ is large enough to resolve the 
signal without overwhelming it. The selected $C$ value minimized artifacts while including the majority of recession data. Smaller values introduced significant artifacts, while larger values excluded recessions from plots. Values for $C$ were tested using 5, 10, 25, 50, and 100 (see appendix).

\subsection{EXPONENTIAL TIME STEP}

A recently introduced approach that advances upon the previously discussed methods is the exponential time step (ETS) approach. Roques et al. (2017) introduced the exponential time step method which constitutes the exponential-like decay of hydrograph recessions by incrementing $\Delta t$ exponentially to estimate $d Q / d t$ (Figure 11). In this method, $Q_{t}$ is the baseflow at any time $t, Q_{0}$ is the initial baseflow and $\mathrm{k}=$ exponential constant. The exponential constant can be expressed in a number of ways. A practical definition is that $k$ is the ratio of the baseflow at time $t_{0}$ to the baseflow one day prior.

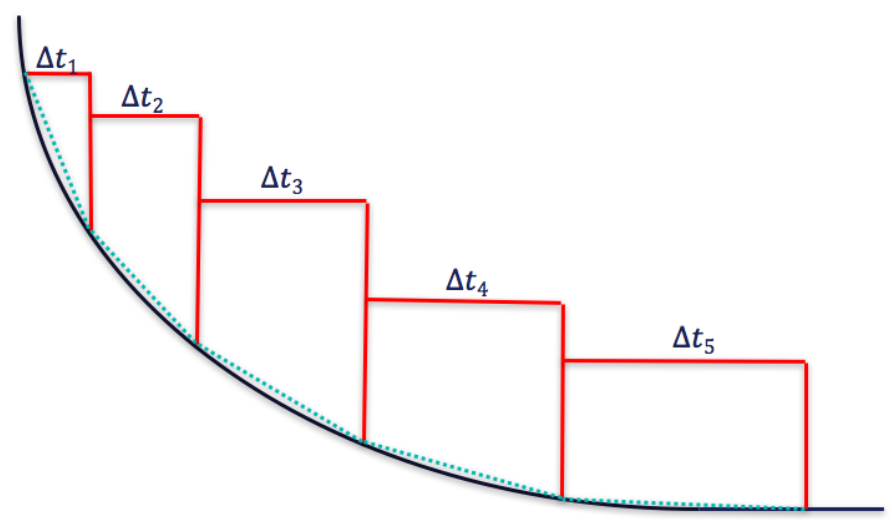

Figure 11 - ETS illustration where the time increment increases exponentially along a recession. 
Resolution of the devices used to measure stream stage can affect the integrity of the data being collected. This can lead to periods of time where no change in flow is reported, or the flow "jumps". This "jump" or lack of change in record can cause artifacts when computing timederivatives of flow. The ETS method sought to solve these issues by implementing increments in the time step exponentially alongside the recession and enumerates the $d Q / d t$ value from a linear regression fit after exponentially incrementing the first approximation of the hydrograph recession. By implementing a linear regression function, the derivative can be estimated such that $d Q / d t$ accounts for all data points in the considered $Q$ and corresponding $t$ intervals.

The ETS method (Roques et al., 2017) applies an increment for an integer $m$,

$$
m(t)=1+\left[n e^{\left(-\frac{1}{\gamma t}\right)}\right]
$$

Equation 5

where $m$ is the number of data values included within an interval $\Delta t_{i}=t_{i+m}-t_{i}$, and $n$ is determined by the user of the method which sets the maximum interval permitted to compute the derivative, such that:

$$
-\frac{d Q}{d t}=\frac{Q_{i}-Q_{i+m}}{t_{i+m}-t_{i}}=f(Q)
$$

Equation 6

The variable $Q(t)$ can be found by fitting an exponential function to the recession where:

$$
Q(t)=Q_{o} e^{-\gamma t}
$$


The variable $\gamma$ determines how quickly a time step will increase along a specific recession and is associated with the baseflow recession constant $K_{b}$ (Roques et al. 2017). For this method, optimization of $d Q / d t$ is found by accounting for all data points within the considered discharge and time intervals. To do this, the derivative is estimated by implementing least-squared linear regression function.

$$
Q(t)=\alpha t+\beta
$$

Taking the time derivative of Equation 10 results in values for:

$$
\begin{gathered}
\frac{d \bar{Q}}{d t}=\alpha \\
\bar{Q}=\frac{\sum_{i}^{i+m} Q}{m+1} \\
R^{2}=1-\frac{\sum_{i}^{i+m}\left(Q_{i}-\widehat{Q}_{l}\right)^{2}}{\sum_{i}^{i+m}\left(Q_{i}-\bar{Q}_{l}\right)^{2}}
\end{gathered}
$$

Equation 10

Equation 11

The $\mathrm{R}^{2}$ factor is used to describe the goodness of fit of the derivative $d Q / d t$. Of the previously mentioned methods, ETS is shown to be robust in regard to eliminating artifacts in recession plots. In the initial study by Roques et al. (2017), ETS methodology is also shown to allow the best representation of entire recessions and coherent results over the entire $n$ parameter due to providing the most robust and consistent estimates for interpreting recession as compared to other studies. ETS did not produce patterns of scatter or large deviations from true recessions and provided the most accurate estimations of $a$ and $b$ parameters as compared to other methods. One drawback found in the original study by Roques et al. (2017) was that while ETS produced 
the most robust results, it was also found to be most sensitive to the considered time step, $n$ that the CTS method held constant. For applying this method to Abers Creek, $n$ was defined as 0.20, or $20 \%$ of the duration of any individual recession. 


\subsection{RESULTS}

As previously discussed, Abers Creek experienced a large increase in population density and building density. With this development, one can expect change to occur in watershed hydrology due to increase in impervious surface and buildout. For this study, extracted daily and sub-daily data (Section 2) was fed into various recession approaches (Section 3) to produce 5-year recession plots depicting recession dynamics over the April - Sept period. The conceptual model (Figure 1) links observed changes in the recession plot to expected physical responses that are commonly associated with urban hydrology (i.e. flashy streamflow, lower baseflow). This study sought to observe changes within the watershed as a result of urbanization through hydrograph recessions with historical data. It was assumed that regardless of the recession methodology used, an observable relationship between discharge and storage would occur in recessions through time. It was also assumed that a shift in recession clouds would occur through time to reflect antecedent conditions. As there was uncertainty as to which method would apply best to this particular dataset, it was imperative to apply more than one for this study.

\subsection{DAILY DATA ANALYSIS}

Daily data for Abers Creek is readily available via USGS Water Data portal for surface water discharge from 1948-1993. Application of recession analysis to daily data is common, and applied here to identify the utility of daily data to discern changes in urbanizing watersheds. 
When analyzing the daily streamflow data for Abers Creek, the constant time step approach produced recession plot data that shifts minimally towards a decreased discharge until 1990. When applying constant time step methodology to daily data a few noticeable results occur (Figure 12). First, a noticeable shift indicating a decrease in watershed storage directly after peak development occurs. This is particularly evident in Figure 12c where 1985 data indicates the lowest discharge values. In 1990, however, a shift towards higher baseflow and storage is apparent. This shift is possibly due to effluent from Plum Borough via the Holiday Park treatment plant. This plant discharges treated effluent into Abers Creek.

Variable time step analysis revealed a reduction in data artifacts as compared to CTS methodology (Figure 13). VTS revealed rather similar results between each year. Recessions are slightly more constrained in 1990 data suggesting increased antecedent conditions.

Exponential time step analysis was not applicable to daily data. In order for this method to be applied, enough data points must remain after removing the first days of a recession in order to fit an exponential curve. Therefore, after these points were removed, there were no longer enough data points left to satisfy this argument. For daily data application, VTS approach provided decreased data artifacts as compared to CTS for Abers Creek data. Limitations occurred with daily data for this study as results are not as clear, as that of sub-daily data, due to less information in daily datasets. 

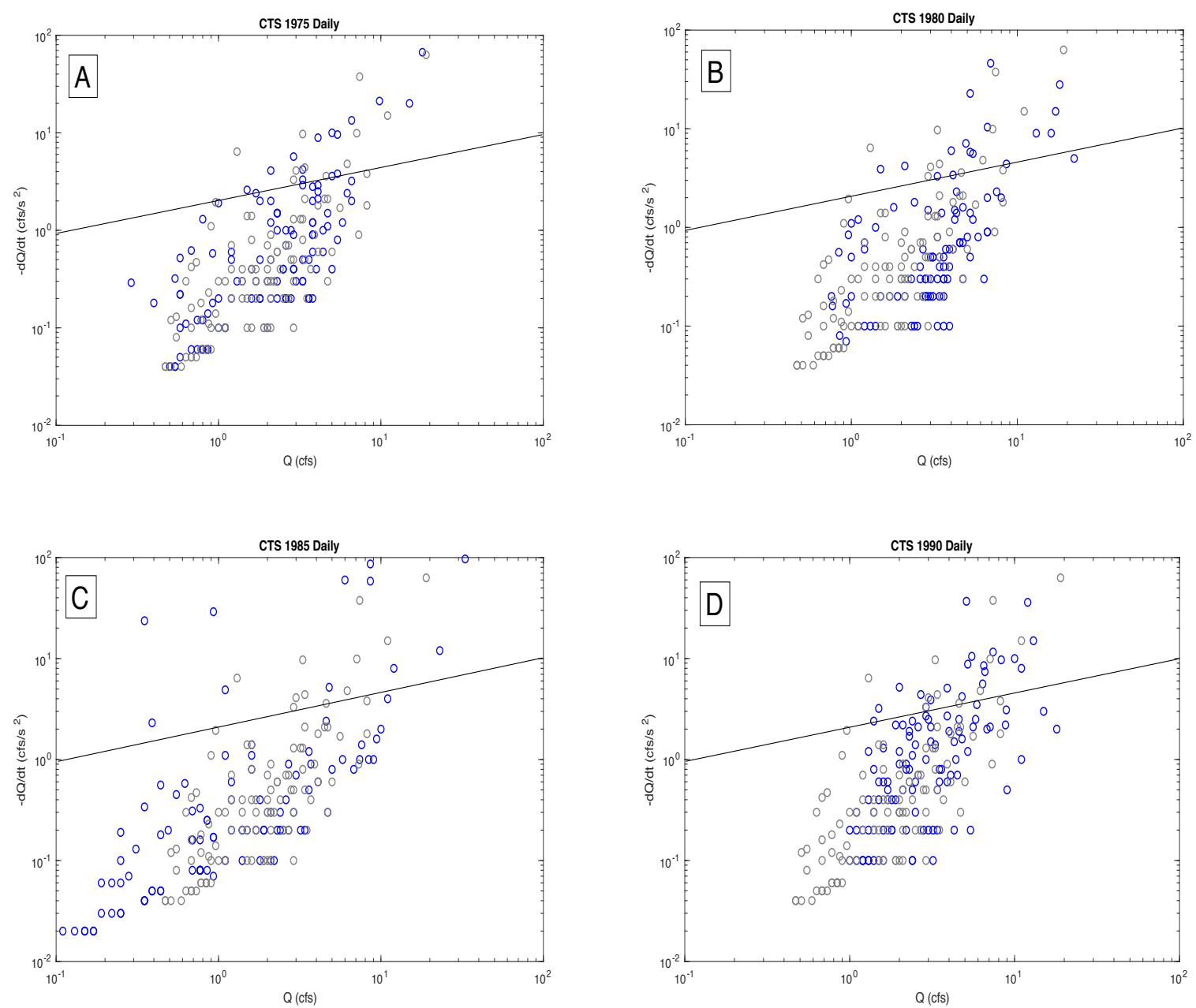

Figure 12 - Daily discharge data processed using constant time step approach. 1970 data was used as a baseline and appears in light grey. While the blue data points correspond to the year as labeled. Artifacts can be observed in the lower portion of the plots.
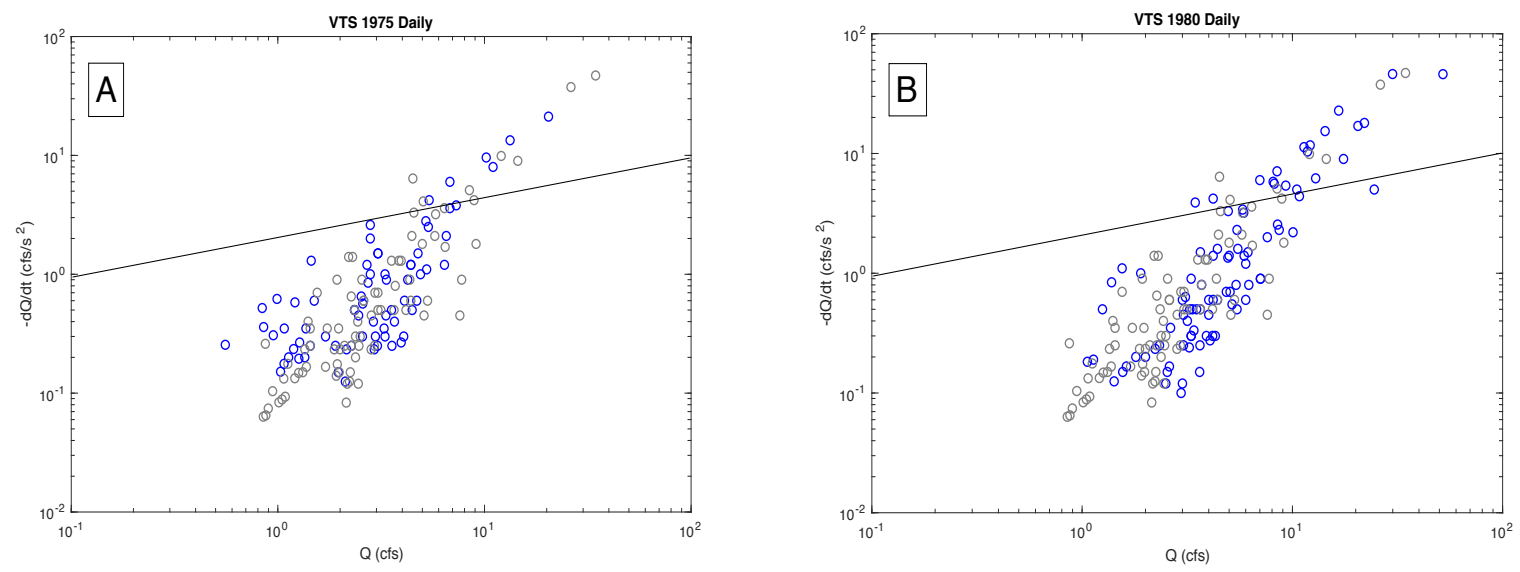

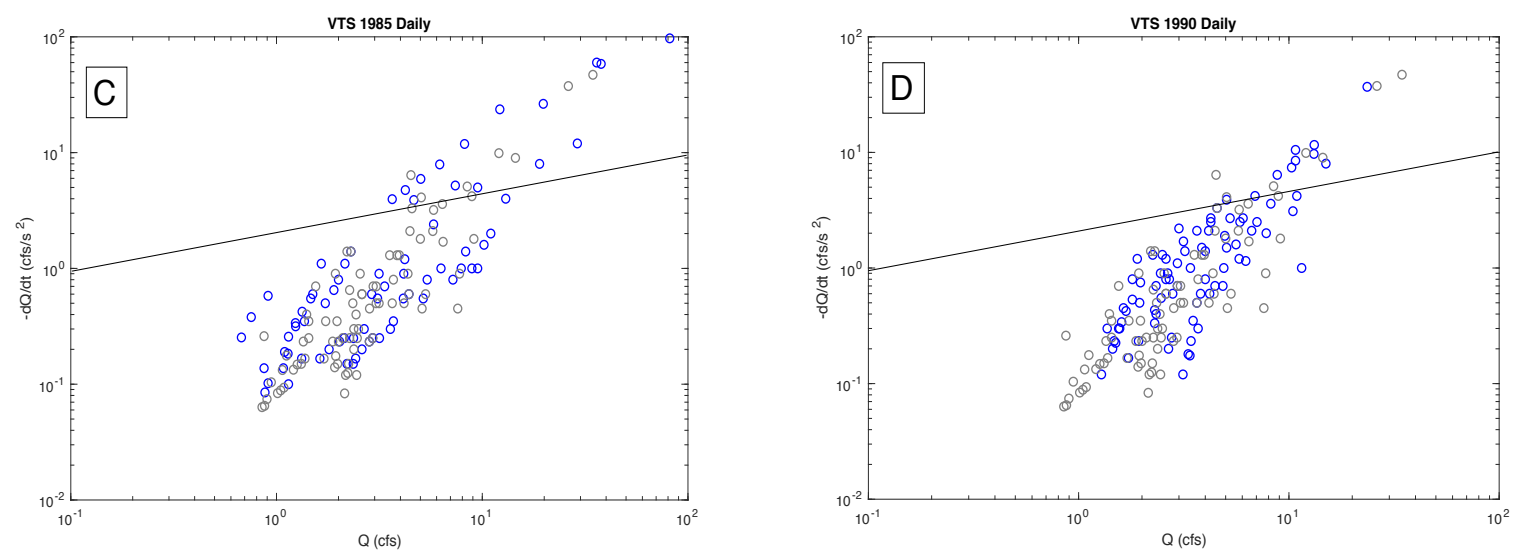

Figure 13 - Daily data using variable time step approach exhibits similar regimes throughout. 1970 data was used as a baseline and appears in light grey (a) 1975, (b) 1980, (c) 1985, (d) 1990.

\subsection{SUB-DAILY DATA ANALYSIS}

\subsubsection{CHANGE IN $Q$}

When applying the CTS approach to sub-daily data (Figure 14), an observable difference is the increase in information as compared to daily CTS plots (Figure 12). In Figure 14, a noticeable decrease in discharge occurs, suggesting a decrease in watershed storage. This is a noteworthy result as a watershed will be in a transient flux given the recorded changes in development within the watershed (Figures 3 and 4), and may take years to return to a steady-state condition. Results for 1975 show that a shift is notable, and can be linked to the timescale of changes in watersheds. With increased urbanization, watershed storage is expected to decrease due to the combination of increased impervious cover and water management schemes that route stormwater out of urbanized regions. Moving from 1975 to 1980, we can observe a slight shift towards increased storage as a function of discharge. This minor shift can possibly be attributed to the decline in 
development as described in Hopkins et al. (2015). The largest shift in $Q$ and $d Q / d t$ is apparent in 1985. Thus, suggesting that as time progressed, water storage decreased much more than observed in 1970.

In the 1990 CTS recession plot, we can observe a shift in the data cloud toward a higher discharge, and therefore increased storage regime. While it might be expected that the lowest watershed storage would occur here due to the watershed being in its most urban state, 1990 was the third wettest year on record for Pennsylvania. This significant increase in precipitation explains the shift towards a higher baseflow discharge as well as the development of the Plum Borough water treatment plant. However, it's also important to point out the constraint in spacing in 1990 recession plots that occurs as compared to previous years. The range of $Q$ depicted in the figures may be linked to watershed constraints. Shaw and Riha (2012) suggest that reduced variability in $Q$ is linked to uniformity of antecedent conditions. The results of the CTS methods identify similar behavior, which using the proposition of Shaw and Riha, suggests that urbanized watersheds such as Abers Creek would theoretically exhibit similar conditions. 

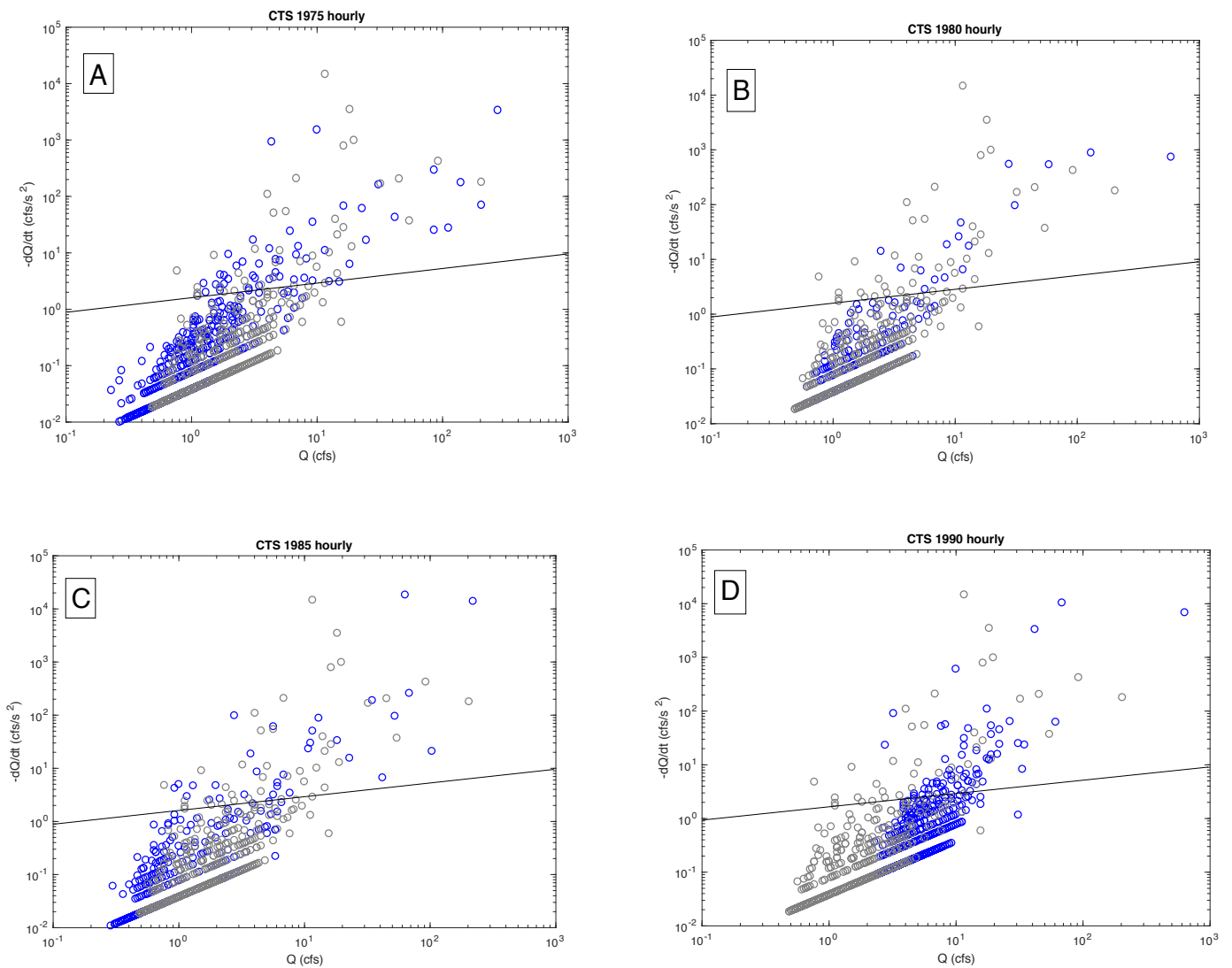

Figure 14 - CTS Sub-daily data: (a) 1975, (b) 1980, (c) 1985, (d) 1990. Grey points correspond to 1970 data. 

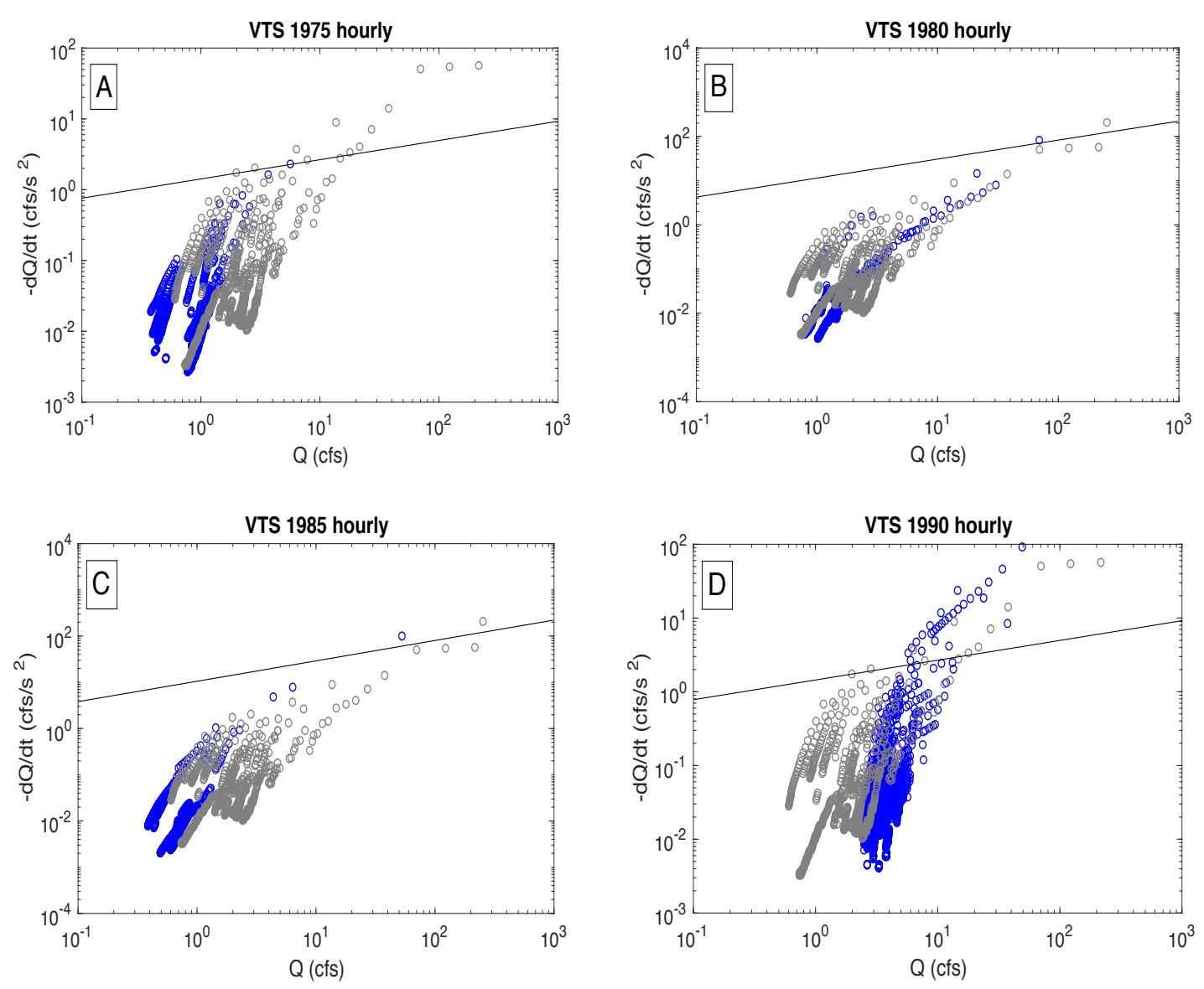

Figure 15 - VTS sub-daily recession plots: (a) 1970, (b) 1975, (c) 1980, (d) 1985, (e) 1990. 

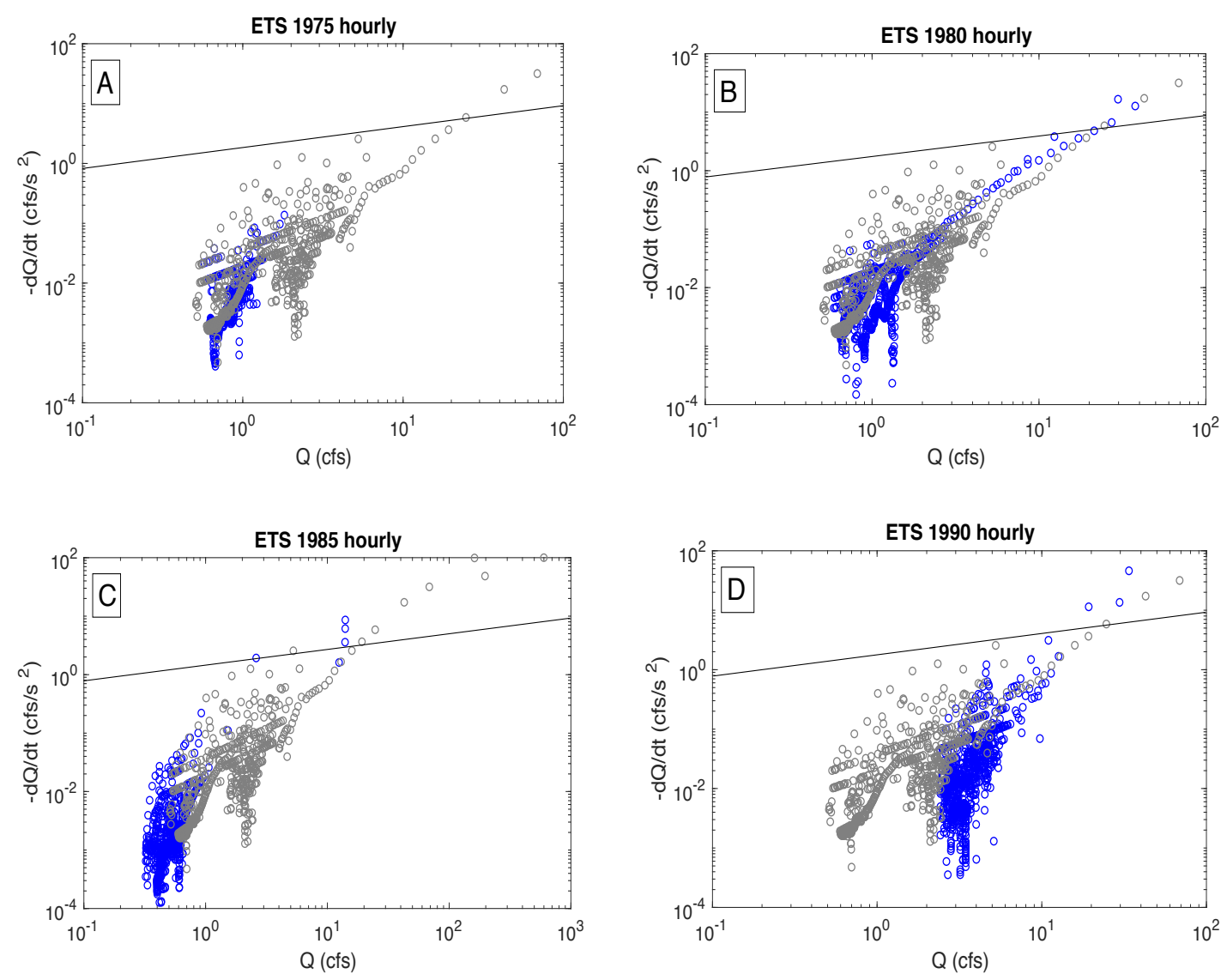

Figure 16 - ETS sub-daily recession plots: (a) 1970, (b) 1975, (c) 1980, (d) 1985, (e) 1990.

Results from VTS methodology on sub-daily data indicate similar trends observed through constant time step, however, VTS pulls out much more information for recessions. In 1970 data (underlain in gray) large variability in discharge occurs in the recession cloud. In 1975 (Figure 15a) an observed shift toward lower baseflow discharge and therefore lower storage are apparent. This shift correlates with the timing of development patterns of Abers Creek. From 1970 to 1975, spread in the recession cloud begins to shift towards being more constrained; e.g. less variability in discharge. In 1980 (Figure 15b) a slight increase in baseflow occurs, also noticeable in other recession methods but then decreases again when progressing to 1985 . Figure 15c, 1985, depicts little variability in discharge regimes. VTS 1990 data (Figure 15d) exhibits significant results. 
While a shift towards higher baseflow and higher storage occurs, the recession cloud is extremely well constrained with little spacing between individual recessions. This is a good indication of increased antecedent conditions from urbanization.

Exponential time step (ETS) exhibited evident results for recession variability and baseflow changes. In Figure 16, high variability in baseflow discharge occurs. The high variability within the recession cloud is not well constrained within the plot and suggests less uniformity in antecedent conditions. An immense difference occurs in 1975 after peak development (Figure 16a) with the data cloud becoming much more constrained towards lower baseflow and storage regimes. This trend attributed with lower baseflow values and constrained data clouds continues through 1980, 1985, and 1990.

To reiterate, an important result, particularly noticeable in VTS and ETS methodology, is the scattering, or lack thereof, of the recession cloud. Through time, the recession cloud appears to become less scattered and more clustered together. This can suggest that antecedent conditions play a large role in the location of recession events within the plot (Shaw et al. 2012). The data cloud can be affected by factors such as human interference; which occurred within Abers Creek (Wang and Cai, 2010). With increased antecedent conditions and more impervious surface clustering of recession data becomes more apparent, especially in 1990 data after major urbanization took place (Figure 15d and 16d). 


\subsubsection{CHANGE IN $d Q / d t$}

A shift towards a higher $d Q / d t$ is indicative of higher streamflow changes. This can be attributed to increased human alteration factors like impervious cover and stormwater management schemes creating peakier flow regimes. A lower $d Q / d t$ state relates to the hydrology of a more natural, less disturbed watershed.

The results depict that there is a general decrease in watershed storage after the height of the development in Abers Creek (1975-1985). Results also depict that the range of discharge is reduced-which can be linked to uniformity in antecedent conditions. This is noticeable within each method, although can be most clearly observed in VTS and ETS approaches for each year up until 1990. Along with a shift in discharge $(Q)$, results also portray a shift in $d Q / d t$, or the time derivative of streamflow. Recessions are shifting down and left towards a lower discharge, $Q$. This shift confirms that with increasing impervious cover as a result of urbanization, watershed storage decreases. In 1990, however, this changes to a shift towards a higher storage regime. This shift is most likely attributed to 1990 being the third wettest year on record (PRECIPITATION RECORDS FOR PITTSBURGH n.d.). When applying methodology, distinct differences in recessions occurs between upper and lower flow regimes and becomes more apparent with time. These results suggest that with different flow regimes, there is sensitivity to change in storage. 


\subsection{CONCLUSIONS}

The key goal of this research was to test the application of hydrograph recession analysis using daily and sub-daily data to evaluate urban impacts. This study provides insight for the characterization of buildout in historical stream data while providing clearer understanding of the behavior of streamflow hydrograph recessions. Results from this study link increased urbanization patterns to changes in hydrology such as shifts in storage as a function of changing baseflow and changes in appearance and location of the recession data cloud. Analysis of sub-daily streamflow records reveal hydrologic changes driven by urbanization, previously only observed over relatively shorter time periods. Refined connections between development history and changes in hydrology allow improved mitigation of stream impacts in urban areas.

Daily data portrayed important links in watershed storage behavior but did not produce the significant shifts in recession clouds as compared to sub-daily results. Sub-daily data provided more robust recession information in terms of baseflow shifts and more noticeable shifts in the data cloud. Results show that through time, variations in discharge become more minimal and shifts in recession clouds towards a lower $d Q / d t$ occurs. With watershed urbanization, we can see noticeable shifts through time in hydrograph recessions regardless of the method applied. Results from methodologies differ as previously assumed. The constant time step approach was least useful for interpreting data for Abers Creek. This negates that other methods are perhaps more useful when analyzing shifts in urban watersheds. Variable time step (VTS) and exponential time step (ETS) methods provided the most favorable results in transposing visible shifts.

To conclude, this study highlights the importance of sub-daily data in recession analysis to extract hydrograph changes that may be linked to urbanization. Insufficient evidence regarding 
hydrograph changes was noted using daily time step observations (Figures 12 and 13). Higher resolution data provides clearer understanding to the relationships driving hydrograph recessions through time and through development (Figures 14, 15 and 16). Moving forward, this study would benefit from further analyses with the use of earlier drum data to provide a critical pre-development hydrology characterization from which to compare later hydrograph changes. 


\section{APPENDIX}

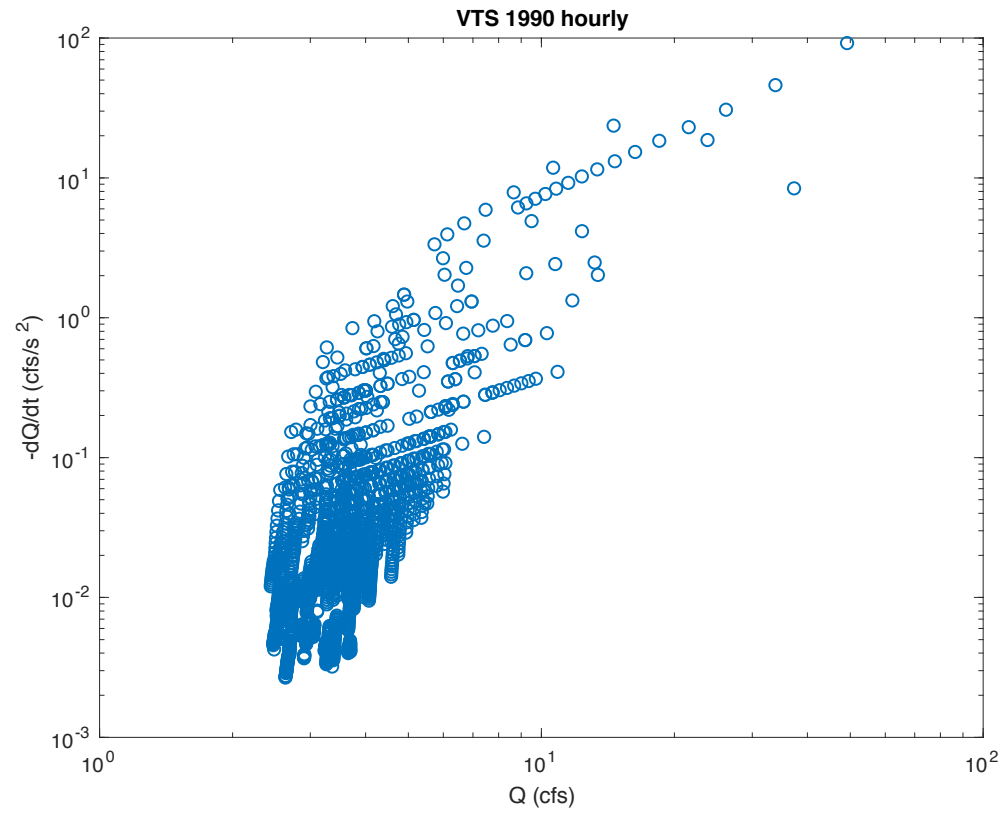

Figure 17 - $C=5$.

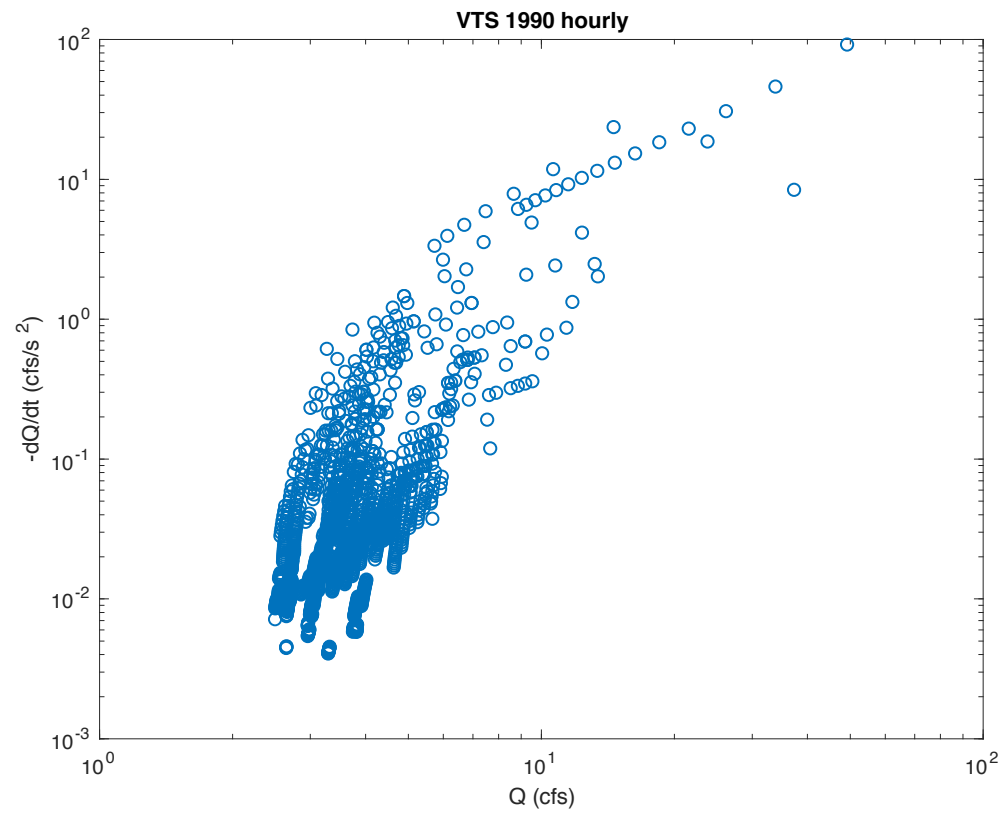

Figure $18-C=10$. 


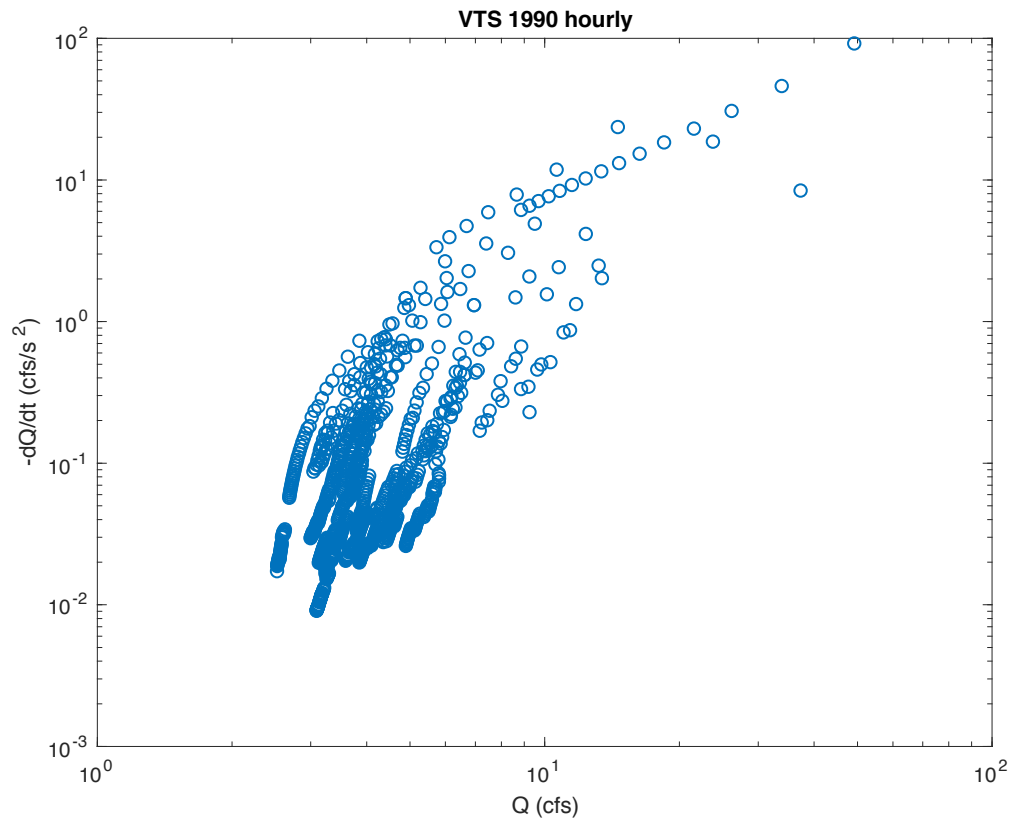

Figure 19 - $\mathrm{C}=\mathbf{2 5}$.

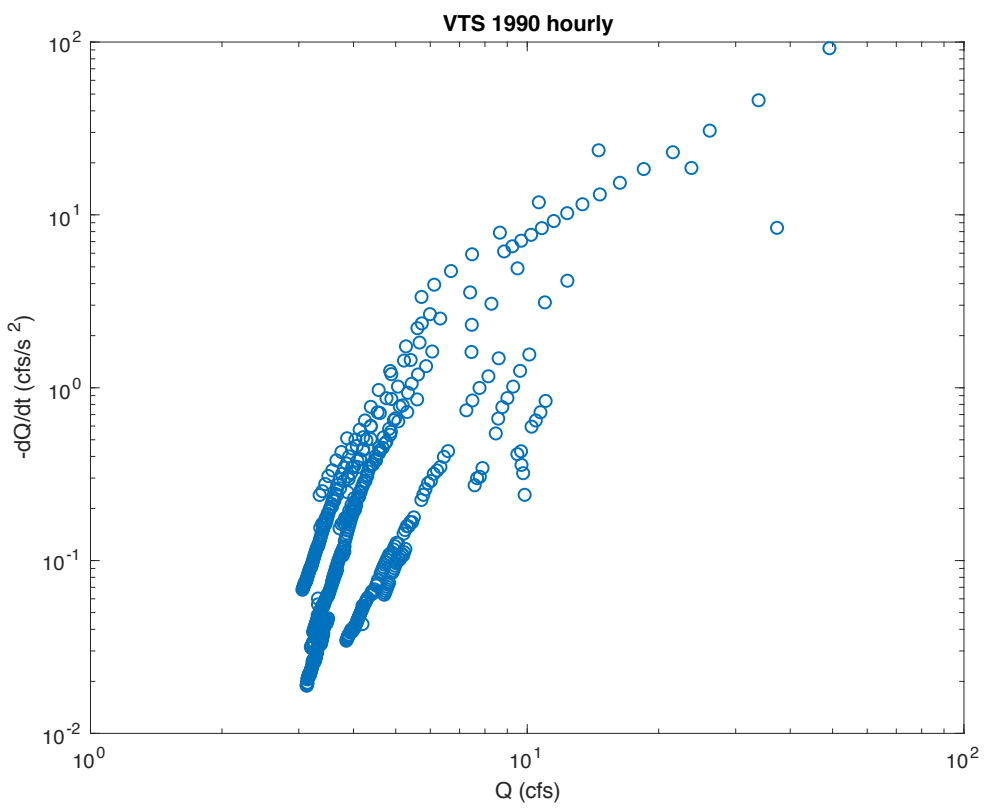

Figure 20 - $\mathrm{C}=\mathbf{5 0}$. 


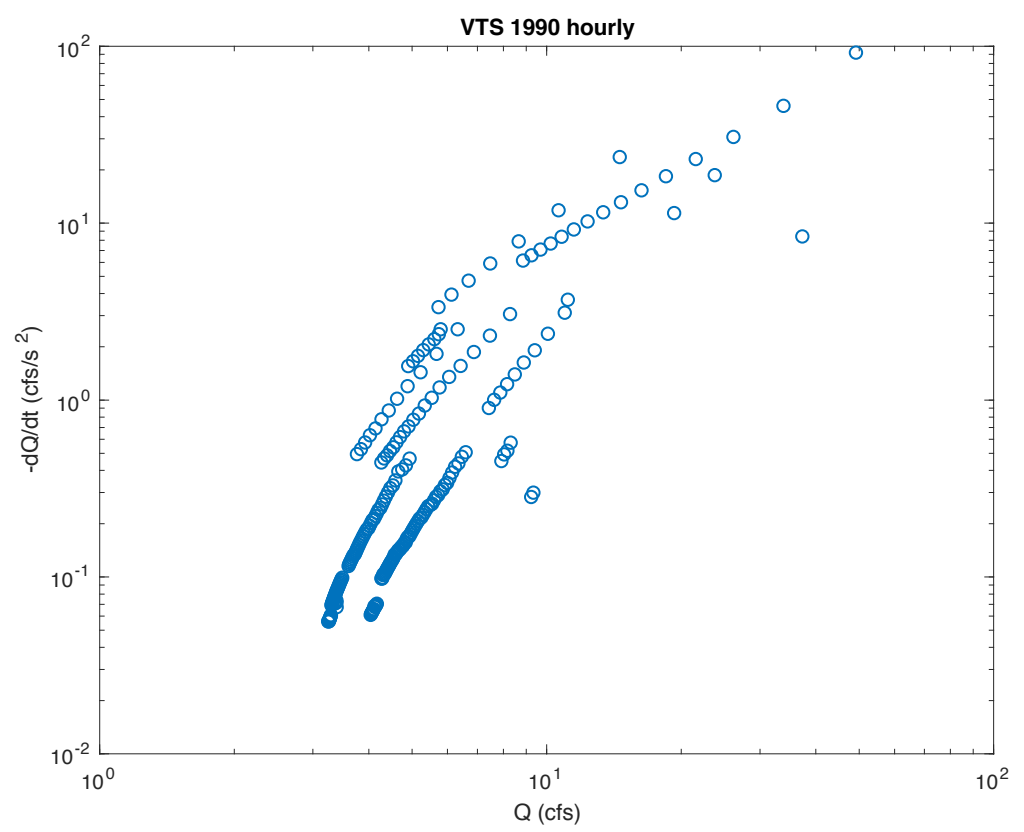

Figure 21 - $\mathrm{C}=100$.

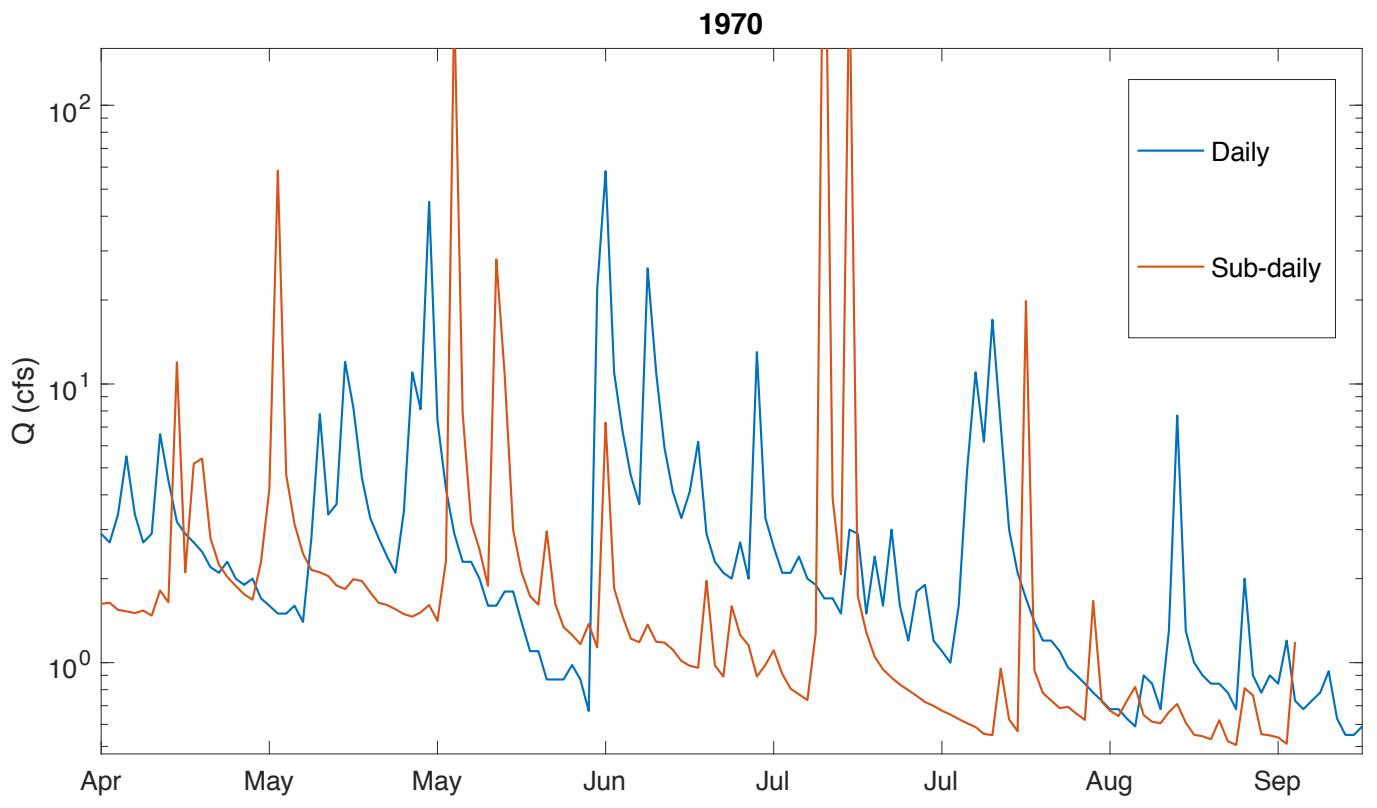

Figure 22 - Comparison of daily (blue) and sub-daily (orange) discharge data for 1970. 


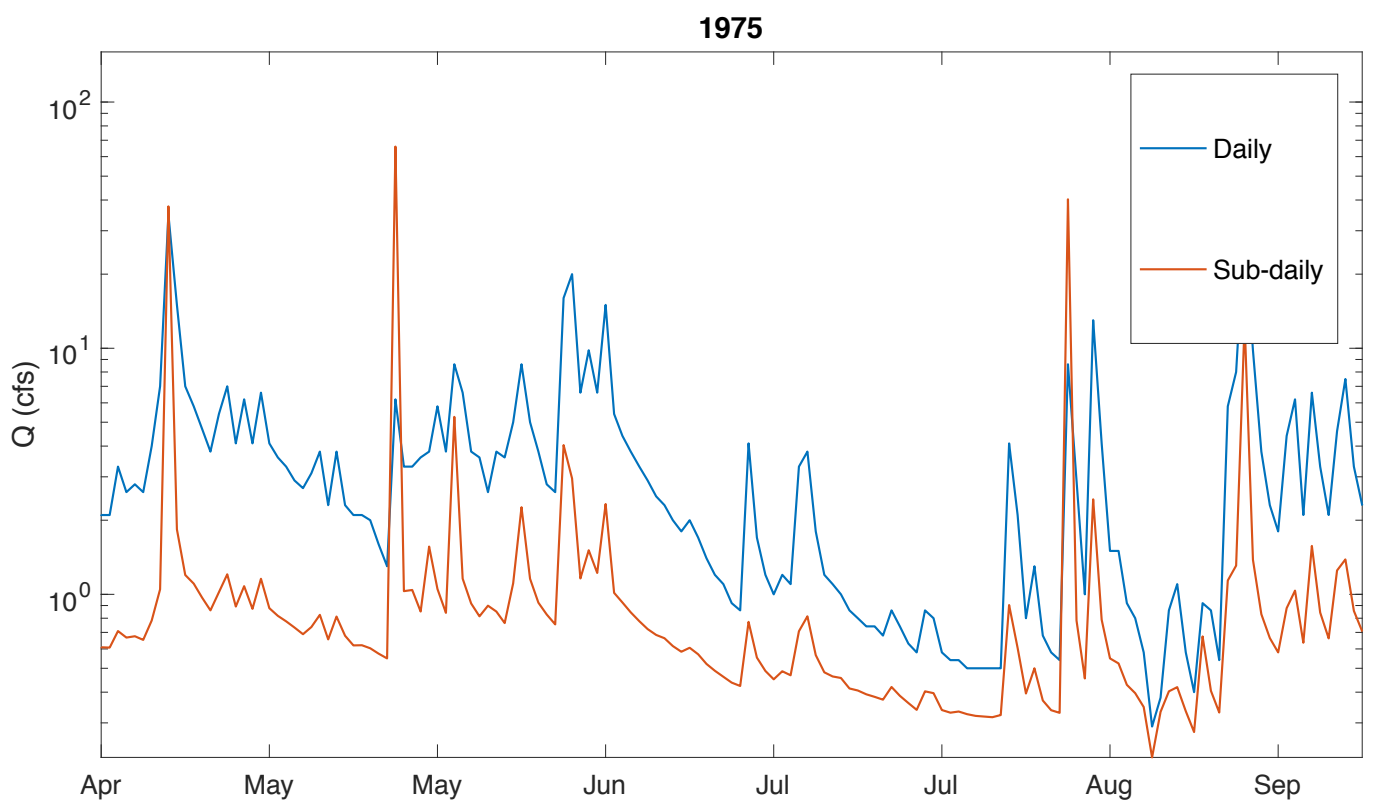

Figure 23 - Comparison of daily (blue) and sub-daily (orange) discharge data for 1975.

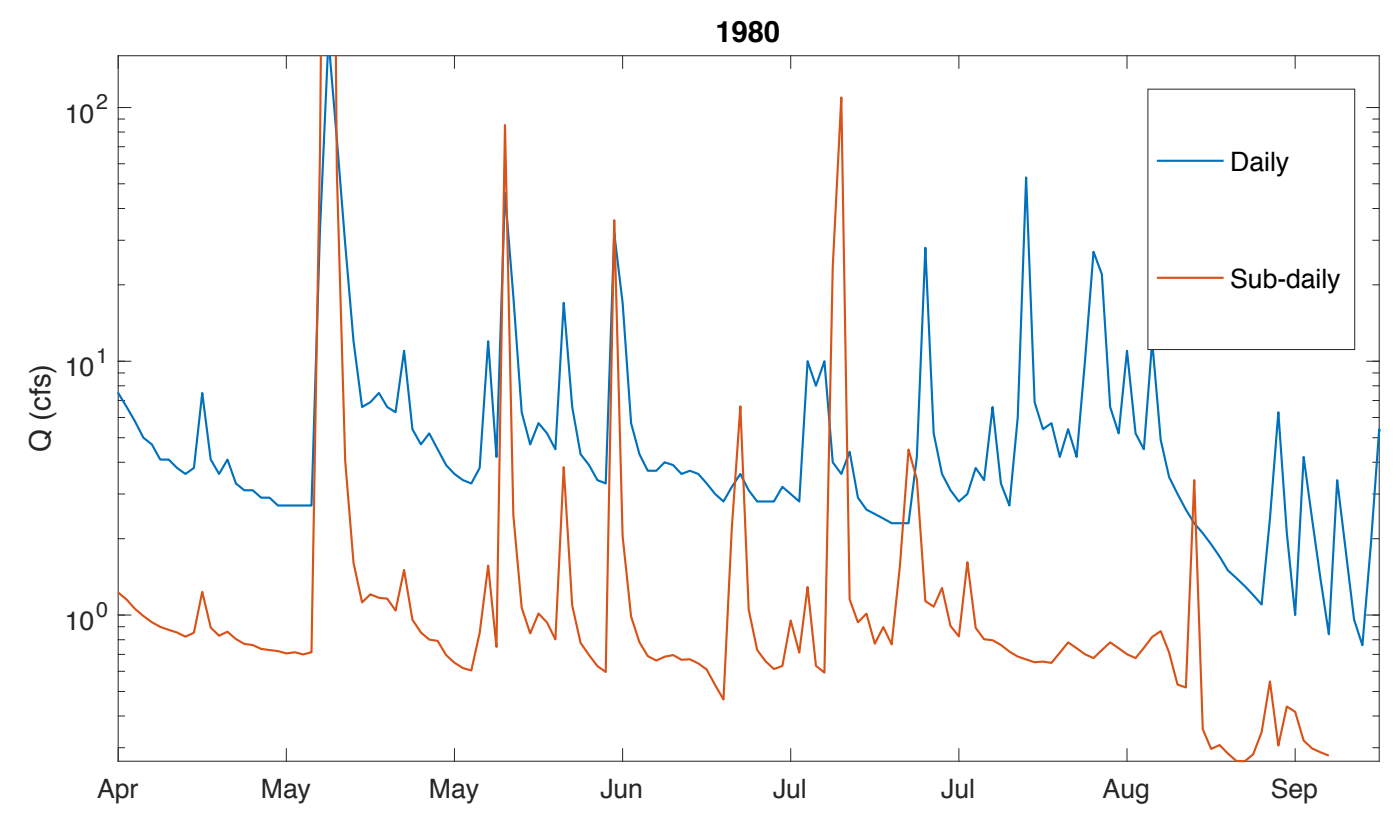

Figure 24 - Comparison of daily (blue) and sub-daily (orange) discharge data for 1980. 


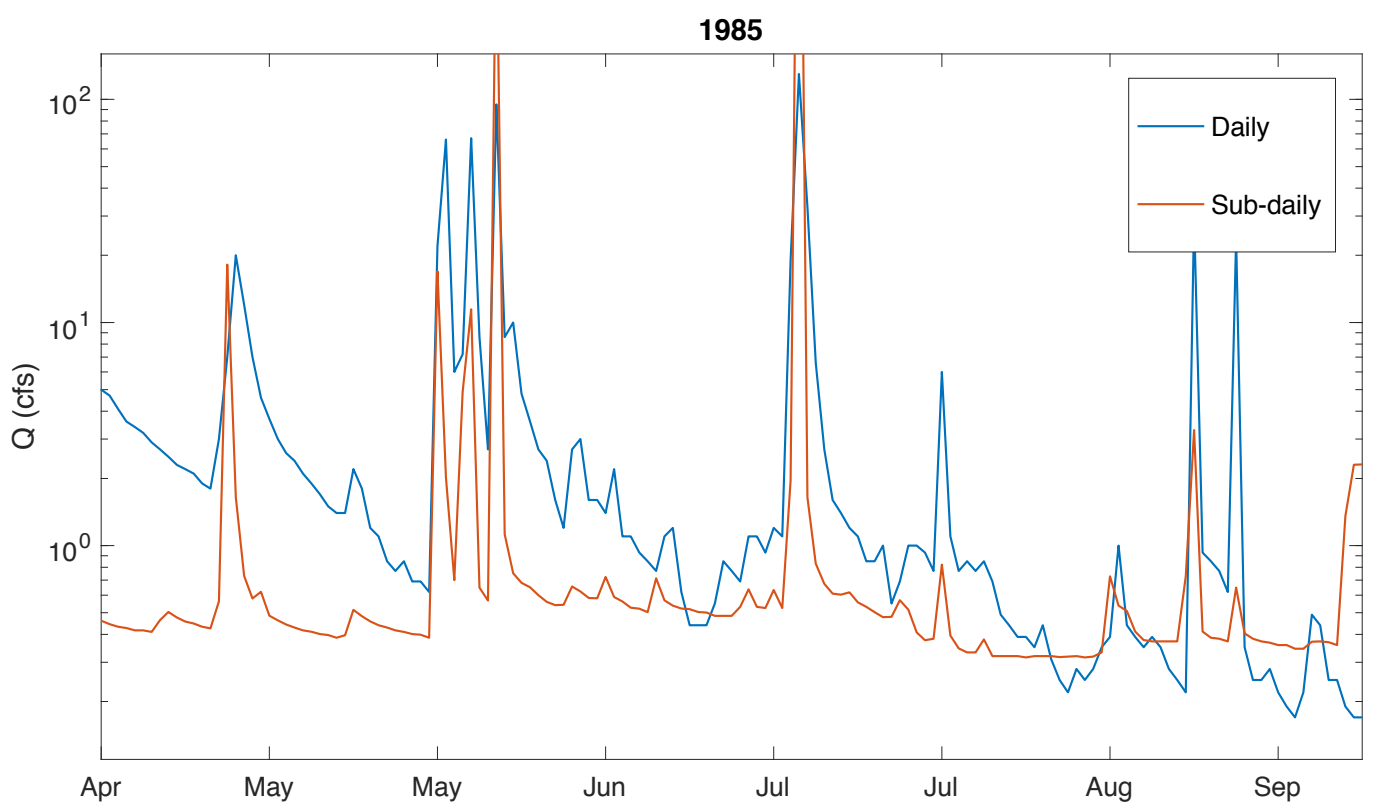

Figure 25 - Comparison of daily (blue) and sub-daily (orange) discharge data for 1985.

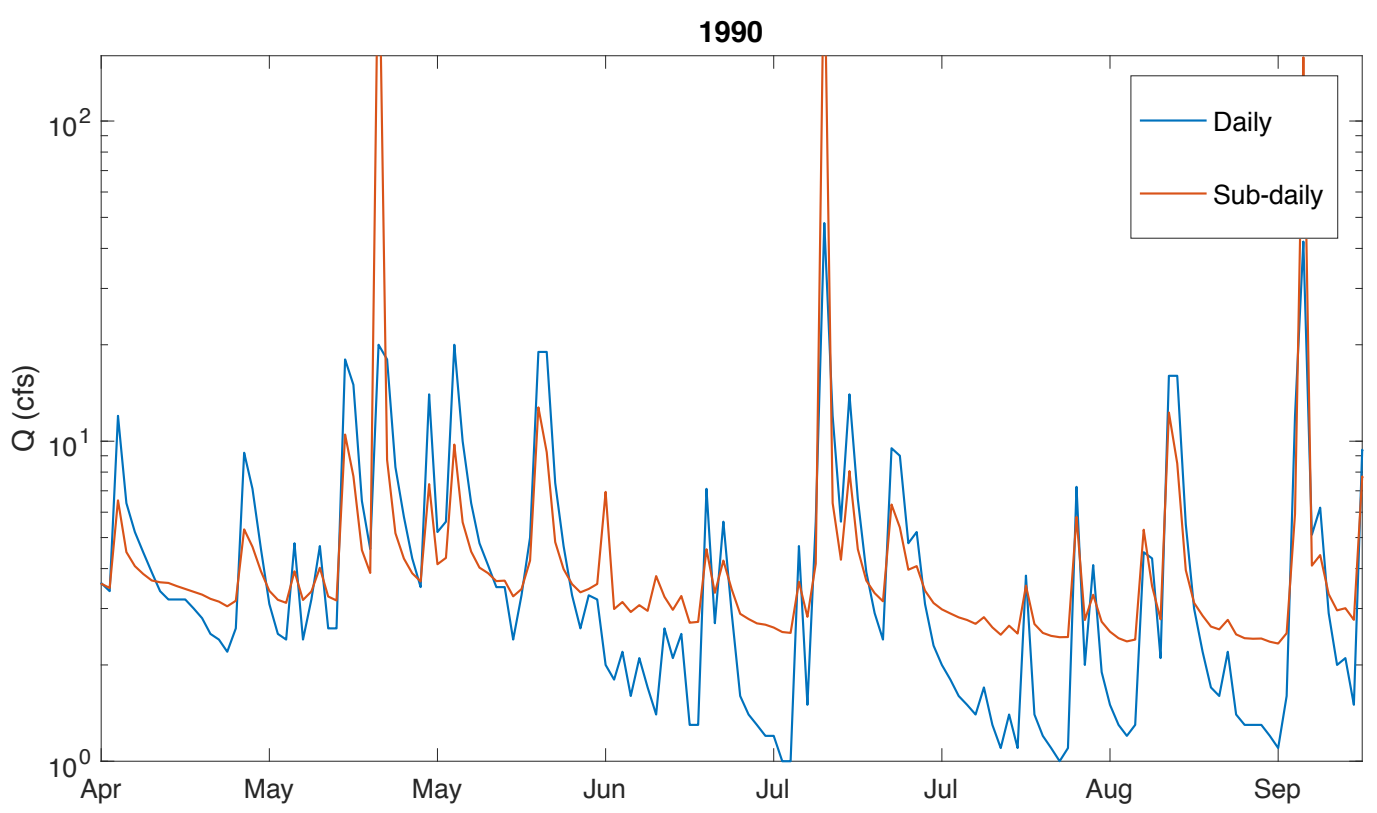

Figure 26 - Comparison of daily (blue) and sub-daily (orange) discharge data for 1990. 


\section{BIBLIOGRAPHY}

Barringer, T. H., Reiser, R. G., \& Price, C. V. (1994). Potential effects of development on flow characteristics of two new jersey streams 1. JAWRA Journal of the American Water Resources Association, 30(2), 283-295.

Bhaskar, A. S., Hogan, D. M., \& Archfield, S. A. (2016). Urban base flow with low impact development. Hydrological Processes, 30(18), 3156-3171.

Biswal, B., \& Marani, M. (2010). Geomorphological origin of recession curves. Geophysical Research Letters, 37(24).

Biswal, B., \& Nagesh Kumar, D. (2014). Study of dynamic behaviour of recession curves. Hydrological Processes, 28(3), 784-792.

Brandes, D., Cavallo, G. J., \& Nilson, M. L. (2005). Base flow trends in urbanizing watersheds of the delaware river basin 1. JAWRA Journal of the American Water Resources Association, 41(6), 1377-1391.

Brutsaert, W., \& Nieber, J. L. (1977). Regionalized drought flow hydrographs from a mature glaciated plateau. Water Resources Research, 13(3), 637-643.

Dralle, D. N., Karst, N. J., Charalampous, K., Veenstra, A., \& Thompson, S. E. (2017). Eventscale power law recession analysis: quantifying methodological uncertainty. Hydrology and Earth System Sciences, 21(1), 65-81.

Fleckenstein, J. H., Krause, S., Hannah, D. M., \& Boano, F. (2010). Groundwater-surface water interactions: New methods and models to improve understanding of processes and dynamics. Advances in Water Resources, 33(11), 1291-1295.

Ghosh, D. (2015). Base Flow Recession Analysis for Streamflow and Spring Flow.

Ghosh, D. K., Wang, D., \& Zhu, T. (2016). On the transition of base flow recession from early stage to late stage. Advances in water resources, 88, 8-13.

Hall, F. R. (1968). Base-flow recessions-A review. Water Resources Research, 4(5), 973983.

Hogan, D. M., Jarnagin, S. T., Loperfido, J. V., \& Van Ness, K. (2014). Mitigating the effects of landscape development on streams in urbanizing watersheds. JAWRA Journal of the American Water Resources Association, 50(1), 163-178.

Hopkins, K. G., Morse, N. B., Bain, D. J., Bettez, N. D., Grimm, N. B., Morse, J. L., \& Palta, M. M. (2015). Type and timing of stream flow changes in urbanizing watersheds in the Eastern US. Elementa: Science of the Anthropocene. 
Kalbus, E., Reinstorf, F., \& Schirmer, M. (2006). Measuring methods for groundwater-surface water interactions: a review. Hydrology and Earth System Sciences Discussions, 10(6), 873-887.

Kirchner, J. W. (2009). Catchments as simple dynamical systems: Catchment characterization, rainfall-runoff modeling, and doing hydrology backward. Water Resources Research, $45(2)$.

Krakauer, N. Y., \& Temimi, M. (2011). Stream recession curves and storage variability in small watersheds. Hydrology and Earth System Sciences, 15(7), 2377-2389.

Liu, G., Schwartz, F. W., \& Kim, Y. (2013). Complex baseflow in urban streams: an example from central Ohio, USA. Environmental earth sciences, 70(7), 3005-3014.

Kroll, C., Luz, J., Allen, B., \& Vogel, R. M. (2004). Developing a watershed characteristics database to improve low streamflow prediction. Journal of Hydrologic Engineering, 9(2), $116-125$.

Meyer, S. C. (2005). Analysis of base flow trends in urban streams, northeastern Illinois, USA. Hydrogeology Journal, 13(5-6), 871-885.

Mutzner, R., Bertuzzo, E., Tarolli, P., Weijs, S.V., Nicotina, L., Ceola, S., Tomasic, N., RodriguezIturbe, I., Parlange, M.B. and Rinaldo, A. (2013). Geomorphic signatures on Brutsaert base flow recession analysis. Water Resources Research, 49(9), 5462-5472.

Network, A. E. S. G. (2004). One Hundred Years of Streamflow Measurements in Massachusetts and Rhode Island.

Patnaik, S., Biswal, B., Kumar, D. N., \& Sivakumar, B. (2015). Effect of catchment characteristics on the relationship between past discharge and the power law recession coefficient. Journal of Hydrology, 528, 321-328.

Precipitation records for Pittsburgh. (n.d.). Retrieved May 23, 2019, from https://www.weather.gov/media/pbz/records/prec.pdf

Roques, C., Rupp, D. E., \& Selker, J. S. (2017). Improved streamflow recession parameter estimation with attention to calculation of- dQ/dt. Advances in water resources, 108, $29-43$.

Rupp, D. E., \& Selker, J. S. (2006). Information, artifacts, and noise in dQ/dt- Q recession analysis. Advances in water resources, 29(2), 154-160.

Schwartz, S. S., \& Smith, B. (2014). Slowflow fingerprints of urban hydrology. Journal of hydrology, 515, 116-128.

Shaw, S. B., \& Riha, S. J. (2012). Examining individual recession events instead of a data cloud: Using a modified interpretation of $\mathrm{dQ} / \mathrm{dt}-\mathrm{Q}$ streamflow recession in glaciated watersheds to better inform models of low flow. Journal of hydrology, 434, 46-54. 
Sophocleous, M. (2002). Interactions between groundwater and surface water: the state of the science. Hydrogeology journal, 10(1), 52-67.

Thomas, B. F., Vogel, R. M., Kroll, C. N., \& Famiglietti, J. S. (2013). Estimation of the base flow recession constant under human interference. Water Resources Research, 49(11), 7366-7379.

Thomas, B. F., Vogel, R. M., \& Famiglietti, J. S. (2015). Objective hydrograph baseflow recession analysis. Journal of hydrology, 525, 102-112.

Toebes, C., \& Strang, D. D. (1964). On recession curves, 1. Recession equations: Journal of Hydrology (New Zealand), 3(2), 2-14.

Toebes, C., Morrissey, W. B., Shorter, R., \& Hendy, M. (1969). Base-flow-recession curves. Water and Soil Division, Ministry of Works.

Troch, P. A., Carrillo, G., Sivapalan, M., Wagener, T., \& Sawicz, K. (2013). Climatevegetation-soil interactions and long-term hydrologic partitioning: signatures of catchment co-evolution. Hydrology and Earth System Sciences, 17(6), 2209-2217.

Vogel, R. M., \& Kroll, C. N. (1992). Regional geohydrologic-geomorphic relationships for the estimation of low-flow statistics. Water Resources Research, 28(9), 2451-2458.

Vogel, R. M., \& Kroll, C. N. (1996). Estimation of baseflow recession constants. Water Resources Management, 10(4), 303-320.

Wagner, W. R. (1970). Geology of the Pittsburgh area (No. 59). Commonwealth of Pennsylvania, [Department of Internal Affairs, Bureau of Topographic and Geological Survey].

Wang, D., \& Cai, X. (2009). Detecting human interferences to low flows through base flow recession analysis. Water resources research, 45(7).

Wang, D., \& Cai, X. (2010). Recession slope curve analysis under human interferences. Advances in Water Resources, 33(9), 1053-1061.

Wang, D. (2011). On the base flow recession at the Panola mountain research watershed, Georgia, United States. Water Resources Research, 47(3).

Wang, D., \& Alimohammadi, N. (2012). Responses of annual runoff, evaporation, and storage change to climate variability at the watershed scale. Water Resources Research, 48(5).

Werner, P. W., \& Sundquist, K. J. (1951). On the groundwater recession curve for large watersheds. IAHS Publ, 33, 202-212.

“What Is a Rating Curve? Why Does It Change over Time?" USGS, www.usgs.gov/faqs/whata-rating-curve-why-does-it-change-over-time?qt-news_science_products=0\#qt-news _science_products. 